\title{
Instability-Driven Benthic Storms below the Separated Gulf Stream and the North Atlantic Current in a High-Resolution Ocean Model
}

\author{
RENÉ SCHUBERT AND ARnE BiAstoch \\ GEOMAR Helmholtz Centre for Ocean Research Kiel, Kiel, Germany \\ MEGHAN F. CRONIN \\ NOAA/Pacific Marine Environmental Laboratory, Seattle, Washington \\ RICHARD J. GREATBATCH \\ GEOMAR Helmholtz Centre for Ocean Research Kiel, and Faculty of Mathematics and \\ Natural Sciences, Christian Albrechts University of Kiel, Kiel, Germany
}

(Manuscript received 13 December 2017, in final form 23 July 2018)

\begin{abstract}
Benthic storms are important for both the energy budget of the ocean and for sediment resuspension and transport. Using 30 years of output from a high-resolution model of the North Atlantic, it is found that most of the benthic storms in the model occur near the western boundary in association with the Gulf Stream and the North Atlantic Current, in regions that are generally collocated with the peak near-bottom eddy kinetic energy. A common feature is meander troughs in the near-surface jets that are accompanied by deep low pressure anomalies spinning up deep cyclones with near-bottom velocities of up to more than $0.5 \mathrm{~m} \mathrm{~s}^{-1}$. A case study of one of these events shows the importance of both baroclinic and barotropic instability of the jet, with energy being extracted from the jet in the upstream part of the meander trough and partly returned to the jet in the downstream part of the meander trough. This motivates examining the 30 -yr time mean of the energy transfer from the (annual mean) background flow into the eddy kinetic energy. This quantity is shown to be collocated well with the region in which benthic storms and large increases in deep cyclonic relative vorticity occur most frequently, suggesting an important role for mixed barotropic-baroclinic instabilitydriven cyclogenesis in generating benthic storms throughout the model simulation. Regions of the largest energy transfer and most frequent benthic storms are found to be the Gulf Stream west of the New England Seamounts and the North Atlantic Current near Flemish Cap.
\end{abstract}

\section{Introduction}

Benthic storms are near-bottom velocity events that are exceptionally strong for a specific location. They contribute largely to the bottom energy dissipation rate, which is proportional to the cube of the near-bottom absolute velocity. The bottom energy dissipation is estimated to be a substantial sink of the global wind power input (Sen et al. 2008; Arbic et al. 2009), and thus, benthic storms are thought to have a large influence on the global energy balance. Benthic storms, which are often associated with strong surface flow variability (Cronin et al. 2013), are also the main drivers of sediment transport (Gardner et al. 2017). The stir-up of

\footnotetext{
Corresponding author: René Schubert, rschubert@geomar.de
}

sediments leads to the development of nepheloid clouds (Kontar and Sokov 1997; Gardner et al. 2017), which have a large impact on the seabed biota and its diversity (Harris 2014). With the realization that global warming is extending into the deep ocean (Purkey and Johnson 2010; Heuzé et al. 2015), plans are being developed for a Deep Ocean Observing System (DOOS; www. deepoceanobserving.org). The prevalence of benthic storms could have important implications for where and how deep ocean measurements should be made.

For this study, we focus on the North Atlantic and, in particular, on the Gulf Stream (GS)-North Atlantic Current (NAC) system. The GS-NAC system is one of the most energetic current systems of the World Ocean (Ferrari and Wunsch 2009). The GS flows along the Eastern Seaboard, separates from the coast at Cape 
Hatteras, and flows into the open ocean, where it is characterized as a strong, narrow, and surfaceintensified current (Watts and Johns 1982; Lee and Cornillon 1996). Immediately downstream of the separation at Cape Hatteras, small-amplitude, rather sinusoidal meanders dominate the variability of the GS (Watts et al. 1995). East of $69^{\circ} \mathrm{W}$, very large meanders can pinch off to form westward-propagating GS rings of various sizes (Parker 1971). Between Cape Hatteras and the New England Seamounts, recirculations on both sides of the GS drive a large downstream increase in GS transport (Worthington 1976; Hogg 1983; Meinen and Luther 2016), which then stays roughly constant until at least $55^{\circ} \mathrm{W}$ (Hendry 1982; Hogg 1992). The increase is mainly due to the barotropic component of the flow (Hogg 1992; Johns et al. 1995). These recirculation gyres are thought to be driven by eddies (e.g., Hogg and Stommel 1985; Marshall and Nurser 1986; Greatbatch 1987; Greatbatch et al. 2010a; Wang et al. 2017) or by vortex stretching associated with the deep circulation (Greatbatch et al. 1991; Zhang and Vallis 2007; Wang et al. 2017). At the Grand Banks of Newfoundland, the GS bifurcates. Its main part reattaches to the bathymetry and flows northward as the NAC, while a smaller portion flows southeastward as the Azores Current (Gould 1985). The NAC tends to be more barotropic than the GS but can also have a baroclinic near-surface core (Lazier 1994; Meinen 2001). North of Flemish Cap, the NAC turns eastward in the "Northwest Corner." There, the NAC is observed to either be a narrow, strong current associated with moreor-less standing eddies or a weaker and broader flow of lower coherence with a rich eddy field (Lazier 1994).

The eddy field of the GS is associated with eddy kinetic energy (EKE) maxima along its climatological mean path that are from one to two orders of magnitude higher than in the surrounding ocean. This was found for the surface EKE, estimated from satellite measurements (Ducet and Le Traon 2001); for the near-bottom EKE, derived from current meter measurements (Bower and Hogg 1992); and for the whole water column at $55^{\circ} \mathrm{W}$, estimated from a combination of a range of measurements (Richardson 1985). Measurements at $55^{\circ} \mathrm{W}$ indicate that below the main thermocline, EKE intensifies toward the bottom.

Both GS and NAC strongly interact with the mesoscale eddy field (e.g., Wang et al. 2017). Major advances in understanding the complex eddy-mean and surfacebottom flow interactions of the GS system were achieved by the Synoptic Ocean Prediction (SYNOP) experiment (Watts et al. 1995; Shay et al. 1995; Johns et al. 1995). The most important result of SYNOP was the discovery of strong, coherent, mesoscale, near-bottom cyclones below large GS meander troughs between $69^{\circ}$ and $66^{\circ} \mathrm{W}$. In this region (the SYNOP central array), a mesoscale-resolving array of 12 moorings was deployed from June 1988 to August 1990 and observed six events of meander trough amplification associated with deep cyclogenesis. Savidge and Bane (1999a) described the main properties of the measured deep cyclones at 3500-m depth below the meander troughs. The cyclones consistently had a radius of about $130 \mathrm{~km}$ and a radius to the maximum velocity of about $55 \mathrm{~km}$. Most of the strong near-bottom velocities could be attributed to these meander trough amplification events. Orbital speeds of up to $0.5 \mathrm{~m} \mathrm{~s}^{-1}$ were measured. Each of the cyclones lasted between 26 and 63 days, comprising $35 \%$ of the record. Anticyclones were also found below meander crests, but were much weaker and less durable, compared to the deep cyclones. Andres et al. (2016) investigated 18 ship cruise transects along Line W (from Woods Hole to Bermuda) between 1994 and 2014. In total, $28 \%$ of the transects observed deep cyclones associated with large meander troughs, confirming the percentage revealed by SYNOP. The deep cyclone events occurred so frequently that they contribute to a time-mean deep cyclone below a time-mean GS trough around $68^{\circ} \mathrm{W}$ for the period of the SYNOP measurements (Cronin 1996; Savidge and Bane 1999a). This was also found by Bower and Hogg (1996) for the SYNOP eastern array around $55^{\circ} \mathrm{W}$, indicating the occurrence of cyclogenesis also in this region.

Baroclinic instability could be identified as the main driver of the deep circular movements in the SYNOP central array (Cronin 1996). The deep cyclones below the GS are the oceanic counterpart of the atmospheric midlatitude low pressure storms below the jet stream (Savidge and Bane 1999b). Idealized baroclinic instability is driven by an amplifying interaction of horizontal wavelike perturbations of a vertically sheared flow that releases available potential energy from the sloping pycnocline that is associated with the vertical shear (Charney 1947; Eady 1949). For the case of a baroclinic upper-troposphere-intensified jet such as the jet stream, the near-bottom perturbations are often closed circulations, while the perturbations of the jet remain dominantly wavelike (Charney 1947). The genesis of cyclones and anticyclones is thus an integral component of the baroclinic instability of a baroclinic jet. Savidge and Bane (1999b) proposed that this is also the case for the GS: wavelike meanders above deep closed circulations. In terms of the driving force, it is mainly the horizontal pressure gradient that accelerates the deep cyclones (Savidge and Bane 1999b). The local sea surface height drop accompanied by the developing near-surface meander trough is not fully compensated by the countering 
vertical displacement of the thermocline, leading to a developing low pressure center below (Savidge and Bane 1999b; Kämpf 2005). Because of the small density stratification in the deep ocean, the low pressure anomaly extends down to the bottom. It sets up a nearly cyclostrophically balanced flow with little variation in the vertical. During the development of the deep cyclones in the SYNOP array, the deep flow was found to be shifted downstream with respect to the near-surface trough, as expected from baroclinic instability theory. Additionally, the flanks of the GS are associated with horizontal shears, which can result in barotropic instability. Both instabilities are accompanied by energy transfers toward the EKE from the mean available potential and kinetic energy of the background currents (MPE and MKE). Cronin and Watts (1996) showed that the GS around $68^{\circ} \mathrm{W}$ released both its MPE and MKE to the eddy field during SYNOP, although the energy transfer due to baroclinic instability was found to be much stronger, compared to the one attributable to barotropic instability.

The reason cyclogenesis occurs frequently around $68^{\circ} \mathrm{W}$ has been attributed to the influence of the topography farther west as well as to upstream impacts of the New England Seamounts and ring-stream interactions (Shay et al. 1995). For still unknown reasons, the destabilization point of the GS has shifted westward in the last two decades, leading to an even more frequent occurrence of deep cyclones (Andres 2016).

The SYNOP experiment greatly changed the view of the coupling between the near-surface and near-bottom ocean in separated baroclinic currents. Moreover, Andres et al. (2016) found indication from tracer measurements at Line $\mathrm{W}$ that the deep cyclones stir and mix deep western boundary current (DWBC) waters from the slope of the Mid-Atlantic Bight into the ocean's subtropical interior. This indicates that the deep quasicircular movements also have an impact on the slopeinterior exchange and thus on the Atlantic meridional overturning circulation.

The SYNOP measurements were restricted to a small region around $68^{\circ} \mathrm{W}$ where the meander troughs tend to form and grow, often breaking off into cold-core rings. In the present study, we show that a high-resolution ocean general circulation model (OGCM) reproduces the cyclogenesis mechanism and properties observed in the SYNOP experiment. This then gives confidence for using the OGCM to investigate the associated energy transfers and their relation to the occurrence of benthic storms in other portions of the GS-NAC system. The main questions of this study are as follows: Where and how often do benthic storms and cyclogenesis occur in the simulated North Atlantic of the high-resolution model used here? What is the spatial pattern of the energy transfer from the background flow into the eddy field during a cyclogenesis event? How is the time-mean energy transfer into the eddy field related to the frequency of benthic storm occurrence?

For this study, we utilize the model output of the ocean general circulation model VIKING20 (Böning et al. 2016). VIKING20 has a horizontal resolution of $1 / 20^{\circ}$ in the GS-NAC region. Shriver and Hurlburt (2000) pointed out that a horizontal resolution above $1 / 16^{\circ}$ is needed to realistically simulate the vertical coupling between the upper and the deep ocean. Kämpf (2005) was able to reproduce the main properties of the cyclones observed in SYNOP using an idealized flatbottom, two-layer model with a horizontal resolution of $5 \mathrm{~km}$. A similar resolution and a partial-cell approach for the bottom cell make VIKING20 a promising candidate for simulating benthic storms, cyclogenesis, and energy transfers.

The paper is organized as follows. The model is described in section 2. Section 3 surveys the occurrence of benthic storms. In section 4, we derive the energy transfers from the slowly evolving background flow to the EKE. Subsequently, in section 5, we show (i) that for a case study, the simulated mechanism of cyclogenesis is similar to that found in the SYNOP observations and (ii) how the energy transfer is spatially related to the meandering GS and the deep cyclones. In section 6, we relate the multiyear-averaged energy transfer to the occurrence of benthic storms and strong increases in deep (anti)cyclonic relative vorticity. Conclusions and discussion are presented in section 7 .

\section{The VIKING20 simulation}

VIKING20 (Böning et al. 2016) is based on the Nucleus for European Modelling of the Ocean (NEMO; Madec et al. 2008) that uses the primitive equations and the hydrostatic and Boussinesq approximations. The model was configured by Behrens (2013) and builds on the global eddy-permitting $0.25^{\circ}$ resolution model configuration ORCA025 (Barnier et al. 2006) that consists of an ocean general circulation model coupled with the viscous-plastic sea ice model Louvain-la-Nueve Ice Model (LIM2; Fichefet and Maqueda 1997). ORCA025 has been developed as part of the European model collaboration DRAKKAR (Barnier et al. 2007). It is discretized on an Arakawa C grid (Arakawa and Lamb 1977). In the horizontal, a tripolar grid with poles at the South Pole and over Canada and Siberia is used to avoid singularities at the geographical North Pole. In the vertical, ORCA025 is discretized on $46 z$ levels with increasing vertical layer thickness with depths 
starting from $6 \mathrm{~m}$ near the ocean surface to a maximum of $250 \mathrm{~m}$. For the bottom cell, a partial-cell approach is used to improve the influence of topography on the ocean dynamics (Barnier et al. 2006). A minimum vertical extent of the bottom grid cell was set at $25 \mathrm{~m}$. The bathymetry is based on the Etopo (www.earthmodels. org/data-and-tool/topography/etopo) and the General Bathymetric Chart of the Oceans (GEBCO; www. gebco.net) products. As sidewall boundary conditions, VIKING20 uses a no-normal-flow condition for the velocity component normal to the boundary and a free-slip condition for the component parallel to the boundary.

For the midlatitude to subarctic North Atlantic $\left(30^{\circ}-\right.$ $85^{\circ} \mathrm{N}$ ), a $1 / 20^{\circ}$ horizontal resolution grid is nested into ORCA025 via the two-way nesting scheme Adaptive Grid Refinement in FORTRAN (AGRIF; Debreu et al. 2008). AGRIF enables an active interaction between both grids. In the nested part of the region of both the subtropical and the subpolar gyres, the grid spacing is smaller than the first baroclinic Rossby radius, which is there found to be between 10 and $40 \mathrm{~km}$ in the model as well as in observations (Chelton et al. 1998). Thus, mesoscale processes are resolved in most open-ocean regions of the high-resolution domain. In the region of GS and NAC, the grid spacing corresponds to horizontal grid scales between 3.5 and $4.5 \mathrm{~km}$ that are even smaller than the second and third baroclinic Rossby radii (Chelton et al. 1998).

Turbulent vertical mixing is simulated with a 1.5 -level turbulent kinetic energy scheme (Blanke and Delecluse 1993). In the case of hydrostatic instability, vertical mixing is parameterized by an enhanced vertical diffusion for tracer and momentum. The lateral viscosity is discretized for momentum by a horizontal bi-Laplacian and diffusion for tracers other than for momentum by an isoneutral Laplacian scheme. A nominal horizontal eddy diffusivity for tracers of $300 \mathrm{~m}^{2} \mathrm{~s}^{-1}$ is used in the base model and $60 \mathrm{~m}^{2} \mathrm{~s}^{-1}$ in the nest, scaled with the grid size. For the horizontal eddy viscosity, a value of $-1.5 \times$ $10^{11} \mathrm{~m}^{4} \mathrm{~s}^{-2}$ is used in the base model and $-6.0 \times$ $10^{9} \mathrm{~m}^{4} \mathrm{~s}^{-2}$ in the nest. For tracer advection, the total variance dissipation (TVD) scheme (Zalesak 1979) is used, and for momentum advection, the energy- and enstrophy-conserving (EEN) scheme (Barnier et al. 2006) is used. For the bottom boundary layer, a diffusive scheme is used with a horizontal mixing coefficient of $1000 \mathrm{~m}^{2} \mathrm{~s}^{-1}$. The bottom friction is parameterized using a nonlinear bottom friction parameterization. The downward flux of horizontal momentum is thereby computed as $C_{D} \mathbf{u}_{h, \mathrm{btm}} \sqrt{u_{\mathrm{btm}}^{2}+v_{\mathrm{btm}}^{2}+\varepsilon}$, where $C_{D}=0.001$ is the bottom drag coefficient; $\mathbf{u}_{h, \mathrm{btm}}=\left(u_{\mathrm{btm}}, v_{\mathrm{btm}}\right)$ is the horizontal velocity vector in the lowest grid cell with the zonal component $u_{\mathrm{btm}}$ and the meridional component $v_{\text {btm }}$; and $\varepsilon=0.0025 \mathrm{~m}^{2} \mathrm{~s}^{-1}$ accounts for bottom turbulent kinetic energy due to tides, internal wave breaking, and other short unresolved time scale currents.

The model was initialized with climatological temperature and salinity fields from Steele et al. (2001). The base model ORCA025 was spun up for 30 years under atmospheric forcing using bulk formulas developed for the Co-ordinated Ocean-Ice Reference Experiments (CORE2; Large and Yeager 2009; Griffies et al. 2009) and then integrated with the high-resolution nest from 1948 to 2009 under the same forcing. Data for the surface forcing were prescribed with 6-hourly (wind speed, humidity, and atmospheric temperature), daily (short- and longwave radiation), and monthly (rain and snow) resolution, with interannual variability. To avoid a long-term model drift, the simulated sea surface salinities are weakly damped toward climatology with a piston velocity of $16.4 \mathrm{~mm} \mathrm{day}^{-1}$, and the precipitation north of $62^{\circ} \mathrm{N}$ is reduced by $10 \%$. For this study, we use 5-day mean model output data. We analyze the model simulation period 1980-2009, when the simulated dynamics have adjusted to the insertion of the highresolution nest.

\section{The frequency and spatial distribution of benthic storms}

In a similar model setup for the greater Agulhas Current region, Cronin et al. (2013) showed a map of the percentage of time that the near-bottom 5-day mean absolute velocity exceeded $0.2 \mathrm{~m} \mathrm{~s}^{-1}$. The metric was also computed using historical moored observations and showed good agreement with the model results. The $0.2 \mathrm{~m} \mathrm{~s}^{-1}$ criterion was motivated in part by engineering considerations for designing a surface mooring for that region, as well as by sediment transport principles. Such a near-bottom velocity is able to lift sand with a density of quartz and a diameter of up to $70 \mu \mathrm{m}$ (Cronin et al. 2013) and generates a large increase in the concentration of particle matter within the bottom boundary layer (Hollister and McCave 1984; Gardner et al. 2017).

In the North Atlantic during the model period 19802009, near-bottom absolute velocities of more than $0.2 \mathrm{~m} \mathrm{~s}^{-1}$ occurred in VIKING20 frequently below the GS-NAC system and in the northwestern Labrador Sea (Fig. 1a). Bottom currents exceeded $0.2 \mathrm{~m} \mathrm{~s}^{-1}$ more than $50 \%$ of the time near the shelf around the subpolar North Atlantic, south of Cape Hatteras, and west of the Strait of Gibraltar. These high probabilities can be attributed to the boundary currents that are associated with average near-bottom speeds of more than $0.2 \mathrm{~m} \mathrm{~s}^{-1}$ (Fig. 1b). 

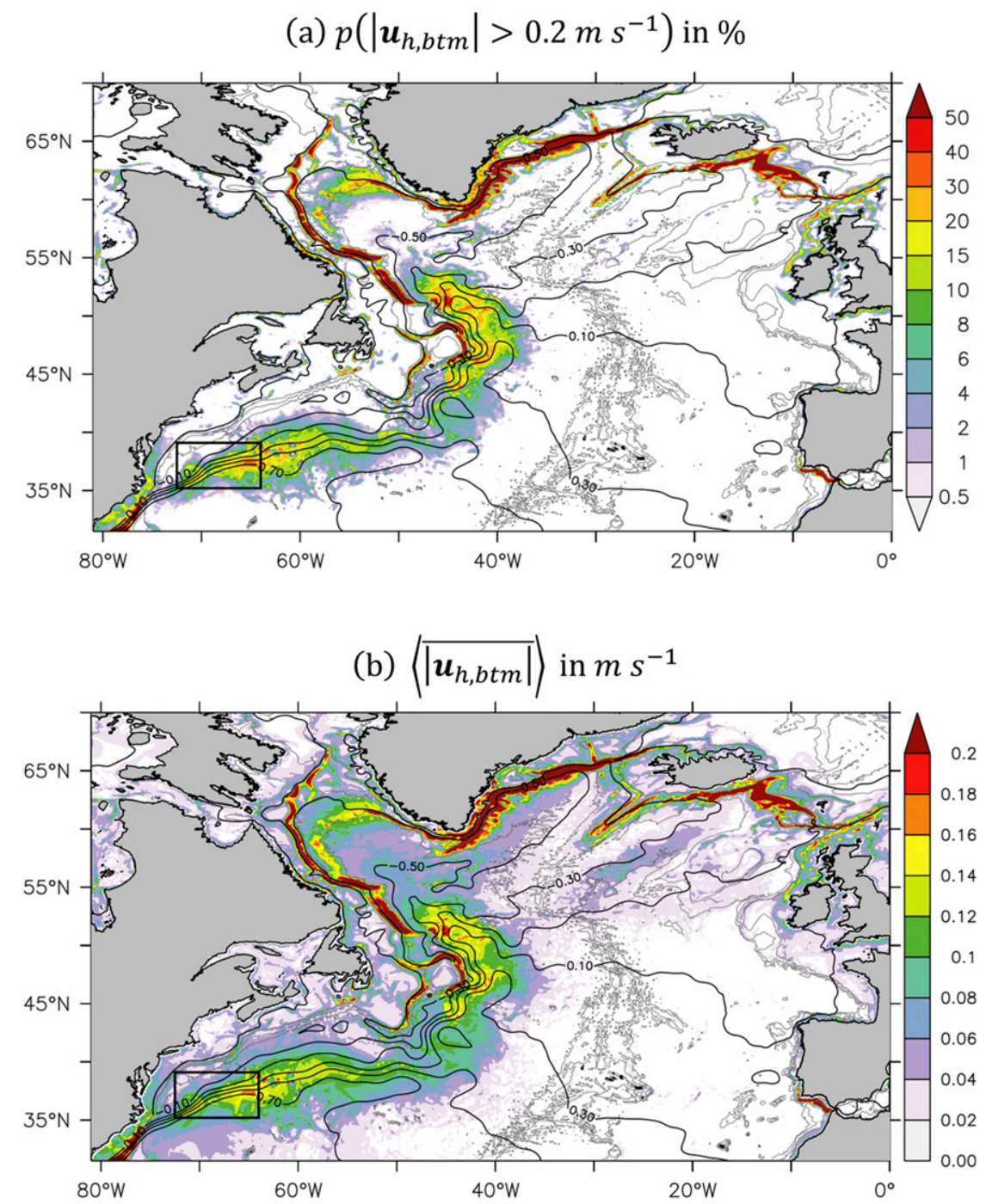

FIG. 1. (a) The percentage that the near-bottom absolute velocity exceeds $0.2 \mathrm{~m} \mathrm{~s}^{-1}$ and (b) the 30-yr-averaged near-bottom absolute velocity for the model period 1980-2009 (color shading). The percentage is derived from 5-day mean model output. In this paper, angle brackets \langle\rangle mark the time mean over the 30-yr average for the period 1980-2009. Thin black contours show the 30-yr-averaged sea surface height $(\mathrm{m})$ with an interval of $0.2 \mathrm{~m}$ for the same period. Gray contours show 500-, 2000-, and 3000-m depth contours. The black box marks the region shown in Figs. 3, 4a, 5, 7, and 8.

Benthic storms are exceptionally strong events for a specific location. One way to exclude the boundary currents from the definition of benthic storms is to define benthic storms as events with $\left|\mathbf{u}_{h, \mathrm{btm}}\right|^{\prime}>0.1 \mathrm{~m} \mathrm{~s}^{-1}$ (i.e., events where the near-bottom velocity exceeds the local annual mean of the respective year by at least $0.1 \mathrm{~m} \mathrm{~s}^{-1}$ ). The threshold has been chosen to identify rare events with probabilities of less than $15 \%$ for nearly the whole North Atlantic. The tick marks the deviation from the annual mean. The probabilities for the condition $\left|\mathbf{u}_{h, \mathrm{btm}}\right|^{\prime}>0.1 \mathrm{~m} \mathrm{~s}^{-1}$ show that the coherent near-bottom currents could be excluded by this threshold (Fig. 2a). Most of the residual structure remains, and its large-scale patterns are similar to the near-bottom EKE (Fig. 2b): enhanced probabilities and EKE values are found directly below the near-surface GS, east of the near-surface NAC, in the Labrador Sea west of Greenland, and southwest of the Denmark Strait (Fig. 2). Highest probabilities for the condition $\left|\mathbf{u}_{h, \mathrm{btm}}\right|^{\prime}>$ $0.1 \mathrm{~m} \mathrm{~s}^{-1}$ are found in a circular pattern east of Flemish Cap $\left(46^{\circ} \mathrm{N}, 41^{\circ} \mathrm{W}\right.$; Fig. 2a), which is also a local maximum in the 30 -yr-averaged near-bottom absolute 

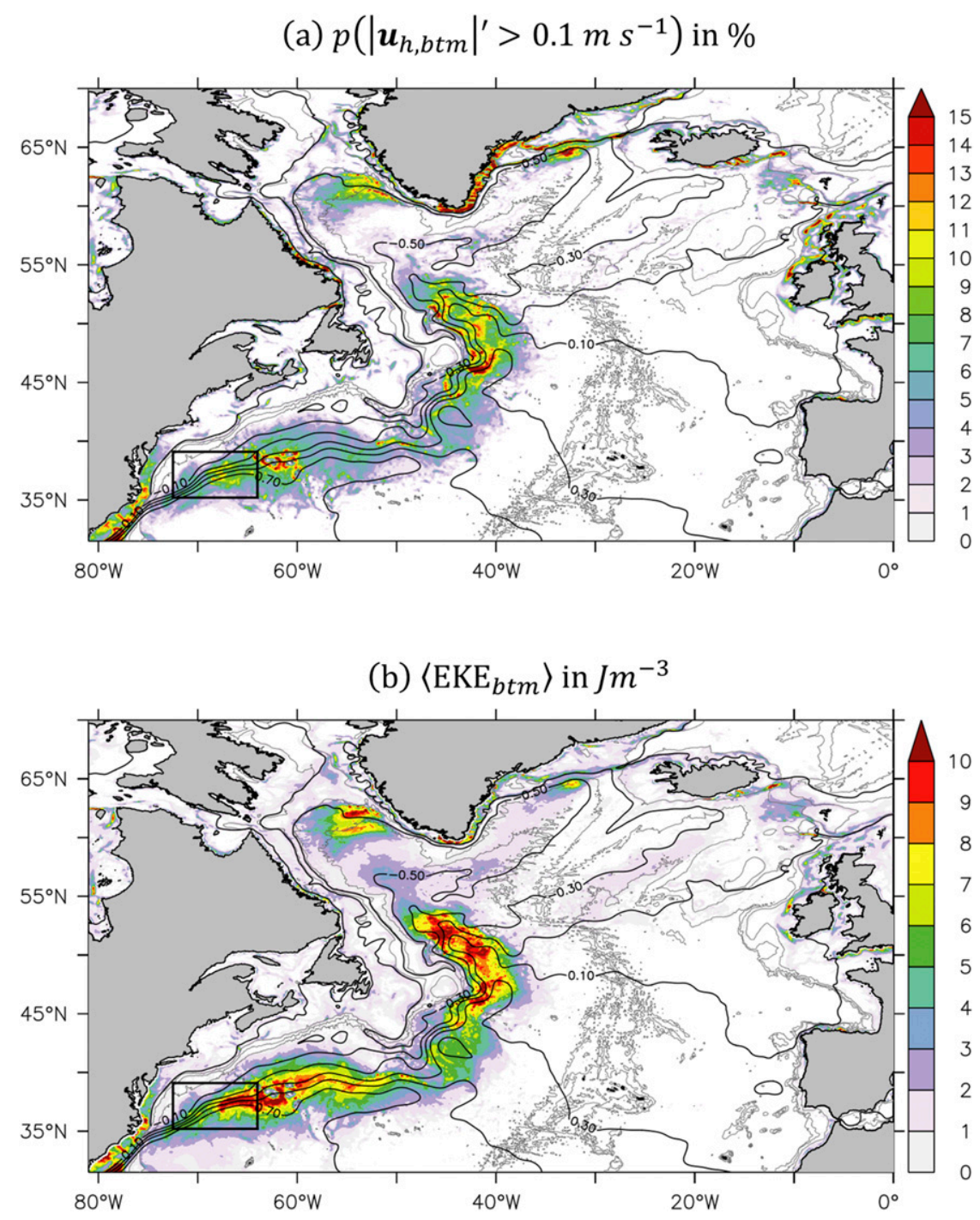

FIG. 2. As in Fig. 1, but the color shading shows (a) the percentage that the near-bottom absolute velocity exceeds its local annual mean by at least $0.1 \mathrm{~m} \mathrm{~s}^{-1}$ and (b) the 30 -yr-averaged near-bottom EKE. The percentage is derived from 5-day mean model output.

velocities (Fig. 1b). Further ring-shaped structures of enhanced near-bottom absolute velocity are found below the NAC around Flemish Cap $\left(44^{\circ} \mathrm{N}, 45^{\circ} \mathrm{W} ; 49^{\circ} \mathrm{N}\right.$, $\left.43^{\circ} \mathrm{W} ; 51^{\circ} \mathrm{N}, 46^{\circ} \mathrm{W}\right)$ and below the early separated GS $\left(36^{\circ} \mathrm{N}, 71^{\circ} \mathrm{W}\right)$. All of these regions are located below a time-mean meander trough of the near-surface current, consistent with frequent cyclogenesis. Further, a region of enhanced near-bottom speed around $37^{\circ} \mathrm{N}, 65^{\circ} \mathrm{W}$, is due to a barotropic signal embedded in the GS.

\section{The derivation of the energy transfers}

The traditional Reynolds eddy-mean flow approach separates the long-time mean and variable circulation.
Here, we are interested in the energy gain of the mesoscale motions due to energy transfer from the slowly varying background flow and not in the energy transfer between the time-mean state and the time-variable field. The eddy-current energy transfers can be achieved by a general separation of the temporal shorter and longer variabilities by dividing the available period into segments of equal length and subsequently applying Reynolds averaging in each of the segments. Variables $X$ are decomposed for each segment into $X=\bar{X}+X^{\prime}$, where the overline marks the time average of $X$ over the segment and the tick the deviation from this average. Note that the temporal resolution of $X^{\prime}$ will be the resolution of the model output, which consists of 
5-day means. Following Rieck et al. (2015), we choose a segment length of 1 year to separate the mesoscale variability (eddies) from variability of longer time scales (background currents). Consequently, eddies by definition include dynamical features like transient whirls, waves, jet streaks, and the annual cycle. In contrast, interannual variability-for example, the year-by-year differences in the position of the Gulf Stream axis-is not included in the eddy field. A separation of the variability of both available potential and kinetic energy into a temporally shorter and a longer part leads to four energy reservoirs, analogous to those of the Lorenz energy cycle (Lorenz 1955): the mean available potential and mean kinetic energy of the circulation varying on interannual and longer time scales (MPE and MKE) and the eddy potential and eddy kinetic energy associated with shorter time scale fluctuations (EPE and EKE). Adjacent reservoirs exchange energy locally and nonlocally.

To derive the local gain in EKE due to energy transfer, first the perturbations of the Reynolds-averaged primitive horizontal momentum equations for $u$ and $v$ have to be multiplied by $\rho_{0} u^{\prime}$ and $\rho_{0} v^{\prime}$ and subsequently added together [see von Storch et al. (2012) for details]. The resulting equation is a time series of the budget for the energy reservoir contributing to the time-mean EKE for each temporal segment:

$$
\begin{aligned}
\mathrm{EKE}_{t}^{\mathrm{ts}}= & -\nabla \cdot\left(\mathbf{u E K E} \mathrm{ts}^{\mathrm{ts}}\right)-\nabla \cdot\left(\mathbf{u}^{\prime} p^{\prime}\right)-\rho_{0} \mathbf{u}^{\prime} u^{\prime} \cdot \nabla \bar{u} \\
& -\rho_{0} \mathbf{u}^{\prime} v^{\prime} \nabla \overline{\boldsymbol{v}}+p_{z}^{\prime} w^{\prime}+\rho_{0}\left(\tau^{x^{\prime}} u^{\prime}+\tau^{y^{\prime}} v^{\prime}\right)
\end{aligned}
$$

where $\mathbf{u}=(u, v, w)$ is the velocity vector with zonal component $u$, meridional component $v$, and vertical component $w$, and $\mathrm{EKE}^{\mathrm{ts}}=0.5 \rho_{0}\left(u^{\prime 2}+v^{\prime 2}\right)$ is the kinetic energy of the eddies for each time step (the index "ts" marks time step-wise values throughout the paper). Partial derivatives $\partial a / \partial b$ are written as $a_{b}$. In (1), $\rho_{0}=1024 \mathrm{~kg} \mathrm{~m}^{-3}$ is the reference density, $p$ is the pressure, and $\tau=\left(\tau^{x}, \tau^{y}\right)$ is the vertical flux of horizontal momentum. In the budget, the $\mathrm{MKE}^{\text {ts }}$ to $\mathrm{EKE}^{\text {ts }}$ energy transfer rate (the barotropic instability term $\mathrm{BTI}^{\mathrm{ts}}$ ) can be identified as the interaction of the Reynolds stress with the mean currents

$$
\mathrm{BTI}^{\mathrm{ts}}=-\rho_{0}\left[u^{\prime} u^{\prime} \bar{u}_{x}+u^{\prime} v^{\prime}\left(\bar{u}_{y}+\bar{v}_{x}\right)+v^{\prime} v^{\prime} \bar{v}_{y}\right] .
$$

The energy transfer due to horizontal Reynolds stress and horizontal background velocity gradients was found to be one order larger than the one due to the vertical stress and gradient. Consequently, the contributions of the vertical Reynolds stress and the vertical gradients have been neglected. The $\mathrm{MPE}^{\text {ts }}$ to $\mathrm{EKE}^{\text {ts }}$ energy transfer rate (the baroclinic instability term
$\left.\mathrm{BCI}^{\mathrm{ts}}\right)$ can be identified as the vertical pressure term $p_{z}^{\prime} w^{\prime}$ in (1). Since the model uses the hydrostatic approximation, it is given by

$$
\mathrm{BCI}^{\mathrm{ts}}=-g \rho^{\prime} w^{\prime},
$$

where $\rho\left(\mathrm{kg} \mathrm{m}^{-3}\right)$ is the in situ density.

The EKE budget is the time mean of the budget time series [(1)] for each temporal (i.e., yearly) segment:

$$
\begin{aligned}
\mathrm{EKE}_{t}= & -\nabla \cdot(\overline{\mathbf{u E K E}})-\nabla \cdot\left(\overline{\mathbf{u}^{\prime} p^{\prime}}\right)-\rho_{0} \overline{\mathbf{u}^{\prime} u^{\prime}} \cdot \nabla \bar{u} \\
& -\rho_{0} \overline{\mathbf{u}^{\prime} v^{\prime}} \nabla \overline{\boldsymbol{v}}+\overline{p_{z}^{\prime} w^{\prime}}+\rho_{0}\left(\overline{\tau^{x^{\prime}} u^{\prime}}+\overline{\tau^{y^{\prime} v^{\prime}}}\right),
\end{aligned}
$$

where $\mathrm{EKE}=0.5 \rho_{0} \overline{\left(u^{\prime 2}+v^{\prime 2}\right)}$ is the annual-mean kinetic energy of the eddies. Further, the annual-mean energy transfer rates are given by

$$
\begin{aligned}
& \mathrm{BTI}=-\rho_{0}\left[\overline{u^{\prime} u^{\prime}} \bar{u}_{x}+\overline{u^{\prime} v^{\prime}}\left(\bar{u}_{y}+\bar{v}_{x}\right)+\overline{v^{\prime} v^{\prime}} \bar{v}_{y}\right], \quad \text { and } \\
& \mathrm{BCI}=-g \overline{\rho^{\prime} w^{\prime}} .
\end{aligned}
$$

Both rates are positive if more energy is transferred from the currents toward the EKE than vice versa during the averaging period of 1 year. Cyclogenesis, as part of mixed barotropic-baroclinic instability, is associated with energy transfers toward the EKE in the upstream half of the meander troughs as well as energy transfers toward the slowly evolving background flow in the downstream half (see section 5 and, in particular, Fig. 5). Temporally averaging the energy transfers of the downor upstream-propagating meanders can lead to a lot of cancellation, limiting the usefulness of the time-mean energy transfers as indicators for cyclogenesis. This occurs especially where the locations of cyclogenesis events are not strongly controlled by topography, and cyclogenesis can evolve freely at different locations (e.g., between the New England Seamounts and the Newfoundland Rise). To avoid this effect, we will investigate the energy gain of EKE due to energy transfer:

$$
\begin{aligned}
\mathrm{BTI}_{+}^{\mathrm{ts}} & =\left\{\begin{array}{ll}
\mathrm{BTI}^{\mathrm{ts}}, & \text { if } \mathrm{BTI}^{\mathrm{ts}}>0 \\
0, & \text { otherwise }
\end{array}, \quad\right. \text { and } \\
\mathrm{BCI}_{+}^{\mathrm{ts}} & =\left\{\begin{array}{ll}
\mathrm{BCI}^{\mathrm{ts}}, & \text { if } \mathrm{BCI}^{\mathrm{ts}}>0 \\
0, & \text { otherwise }
\end{array} .\right.
\end{aligned}
$$

The positive energy transfers can then be interpreted as an indicator for cyclogenesis at the locations of enhanced positive transfers as well as immediately downstream to a distance of one cyclone radius. If benthic storms are only driven by cyclogenesis as part of the baroclinic instability of a jet with downstreampropagating meanders, regions of frequent benthic storms and strong near-bottom EKE are expected to be 
(a) FEB 11, 1990

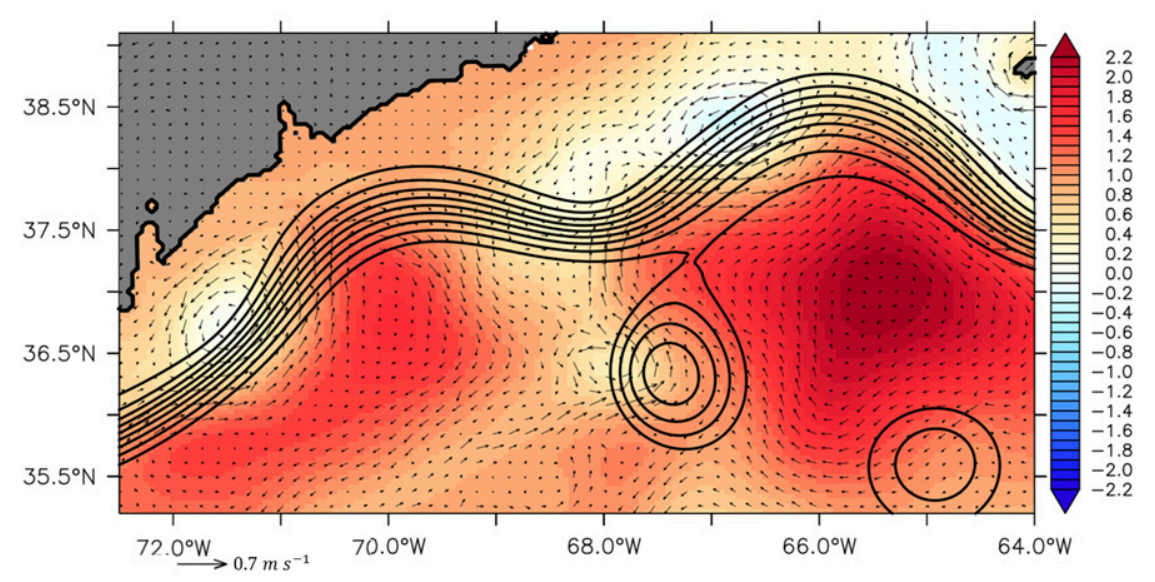

(b) MAR 23, 1990

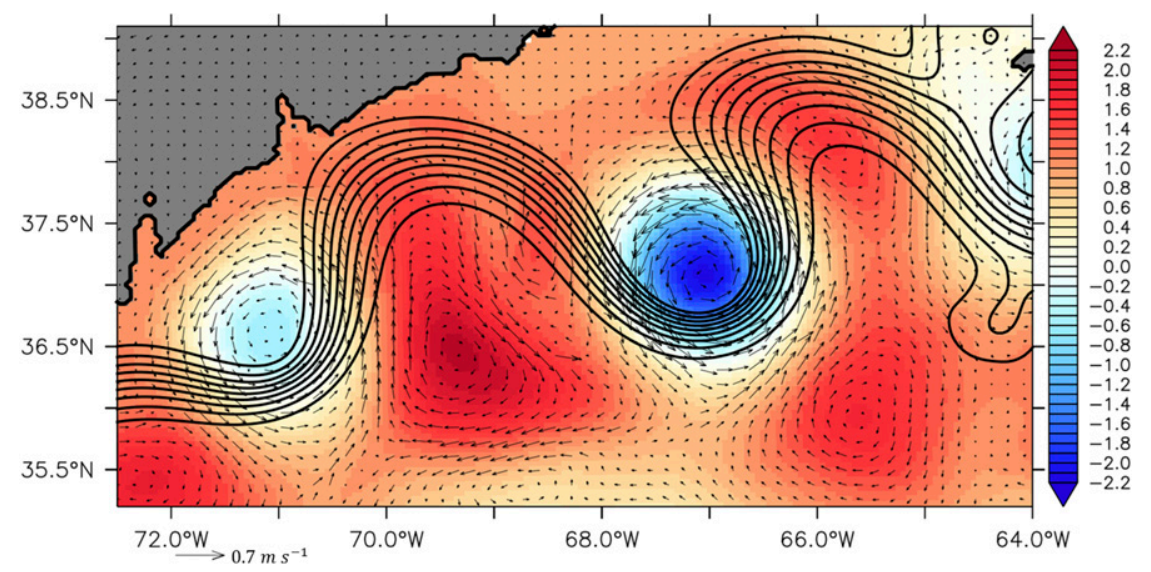

FIG. 3. The 5-day mean pressure $(\mathrm{kPa})$ at $3174-\mathrm{m}$ depth reduced by $33424.1 \mathrm{kPa}$ below the Gulf Stream west of the New England Seamounts around the model dates (a) 11 Feb and (b) 23 Mar 1990 (color shading). The region is marked in Fig. 2. Sea surface height (black contours; contour interval is $0.1 \mathrm{~m}$ from -0.3 to $0.5 \mathrm{~m}$ ) and horizontal bottom velocities (arrows) are shown.

located below enhanced positive energy transfers, as well as immediately downstream down to a distance, where the developing cyclones have dissipated. The traditional energy transfer terms BCI and BTI are sources of EKE growth along mean streamlines of the flow, while $\mathrm{BCI}_{+}^{\text {ts }}$ and $\mathrm{BCI}_{+}^{\text {ts }}$ are local $\mathrm{EKE}^{\text {ts }}$ sources. Because $\mathrm{BTI}_{+}^{\text {ts }}$ and $\mathrm{BCI}_{+}^{\text {ts }}$ are nonnegative, their annual means $\left(\mathrm{BTI}_{+}\right.$and $\left.\mathrm{BCI}_{+}\right)$multiplied by 1 year give the total amount of EKE gain during this year.

\section{Simulated deep cyclogenesis}

For model validation, in this section we show how deep cyclogenesis is simulated in the region of the
SYNOP measurements during a very strong cyclogenesis event in spring 1990 and compare it to the SYNOP measurements and theory. Subsequently, we evaluate the energy transfers into and out of the EKE during the process. In the simulation, around 11 February 1990, a small GS meander trough develops around $68^{\circ} \mathrm{W}$ (Fig. 3a). A small, deep cyclone develops simultaneously around $67^{\circ} \mathrm{W}$. The shift in the perturbations is about a quarter meander wavelength, which is the most favorable to growth (Cushman-Roisin 1994) and thus a good indicator for baroclinic instability. Consequently, both the meander and the deep cyclone grow rapidly.

In the following, we analyze a 5-day mean model output around 23 March 1990, when the deep cyclone 
reached its mature stage and the energy transfer toward the eddy field is strongest. At this stage, the deep cyclone around $67^{\circ} \mathrm{W}$ is almost collocated with the surface trough (Fig. 3b). The radius to the maximum nearbottom velocities is about $55 \mathrm{~km}$ - a typical radius of the measured deep cyclones in SYNOP (Savidge and Bane 1999a). The maximum near-bottom velocity is $0.65 \mathrm{~m} \mathrm{~s}^{-1}$. A major driver of the deep cyclones is the horizontal pressure gradient in the deep, subthermocline layer that is driven by sea surface height changes, which are not fully compensated by the countering vertical displacement of the main thermocline (Savidge and Bane 1999b; Kämpf 2005). Below the thermocline, the pressure gradient forcing extends nearly barotropically to the bottom and sets up a nearly geostrophically balanced flow throughout the water column. Consistently, the simulated near-bottom flows follow more or less the isobars at about 3000-m depth (Fig. 3). The cyclone around $67^{\circ} \mathrm{W}$ is associated with positive relative vorticity of up to $0.2 f$ at 3000-m depth (not shown), indicating important ageostrophic contributions to the flow. One of these ageostrophic components is the centripetal acceleration that strengthens deep cyclones but weakens deep anticyclones and results in a gradient wind momentum balance (Kämpf 2005). At the analyzed model time step, consistently, the deep anticyclones below meander crests are much weaker than the deep cyclones below meander troughs (Fig. 3), and the amplitude of the negative relative vorticity of the deep anticyclones is much weaker than for the positive of the deep cyclones (not shown). The signs of the relative vorticity extrema are consistent with the vertical stretching and squeezing of the water column in the vicinity of a sloping thermocline analogous to the idealized baroclinic instability mechanism, presented by Phillips (1951), based on a two-layer fluid with a sloping interface.

The deep cyclone-meander trough system around $67^{\circ} \mathrm{W}$ is associated with an intense vertical secondary circulation. The vertical velocity is directly related to the horizontal velocity divergence $\left(u_{x}+v_{y}\right)$ by the Boussinesq-approximated continuity equation $-w_{z}=$ $u_{x}+v_{y}$. In the eastern half of the near-surface meander trough, the GS shows a strong divergence, and in the western part, a strong convergence (Fig. 4a). The divergence takes place mainly in the upper $700 \mathrm{~m}$, above the thermocline, and is compensated by upward vertical velocities in the eastern part and by downward vertical velocities in the western part of the cyclone (Fig. 4b). A second meander trough and deep cyclone pair west of $70^{\circ} \mathrm{W}$ shows a similar pattern. The vertical velocities are coherent over the whole water column and have a maximum below the thermocline at 700-m depth of up to $151 \mathrm{~m} \mathrm{day}^{-1}=0.17 \mathrm{~cm} \mathrm{~s}^{-1}$ (Fig. 4b). Our results are consistent with vertical velocity fields at 700-m depth derived from SYNOP measurements by Lindstrom et al. (1997), who diagnosed frequently occurring up- and downward motions of $\pm 170 \mathrm{~m} \mathrm{day}^{-1}$. Further, our simulated divergence patterns are consistent with observed estimates of Savidge and Bane (1999b). Similar to their pattern, we see in Fig. 4a strong upwelling in the downstream half of the cyclone and strong downwelling in the upstream half. It should be emphasized that the secondary circulation is associated with cross-frontal flow at the thermocline level (i.e., within the GS jet): the upwelling (including the horizontal circulation) crosses the front from the warm side to the cold side, and the downwelling crosses from the cold side to the warm side, thereby releasing available potential energy (Bower and Rossby 1989; Donohue et al. 2010).

Near-bottom vertical velocity extrema of similar amplitude, compared to the near surface, are found and can be related to the pattern of the horizontal divergence below 3000-m depth. The near-bottom divergence pattern can be attributed to downhill and uphill near-bottom flow along the sloping bottom (not shown). The deepest SYNOP measurements of the velocity field were at $3500-\mathrm{m}$ depth. Thus, the vertical velocities and associated divergence structures below 3500-m depth are new and cannot be directly compared to the SYNOP measurements. Further, the simulation shows an increase in cyclone maximum velocities toward the bottom below 3500-m depth, which also could not be observed by the single bottom depth SYNOP measurements. This is consistent with an increasing EKE toward the bottom below 2500-m depth derived by Richardson (1985) at $55^{\circ} \mathrm{W}$ - under the assumption that the vertical structure of the deep cyclones is similar for the regions around $67^{\circ}$ and $55^{\circ} \mathrm{W}$.

Next, we examine the time step-wise energy transfers computed from the departures from the annual mean for 1990 using (2) and (3) without applying time averaging to the energy transfer terms. Our results show that the energy transfers are strictly confined to the GS and its shears (Fig. 5). Both the potential and the kinetic energy of the (annual mean) background current are transferred into the eddy field in the upstream half of meander troughs and crest and out of the eddy field in the downstream half. The trough around $67^{\circ} \mathrm{W}$ is nevertheless associated with a net release of available potential and kinetic energy of the GS. The $\mathrm{BTI}^{\mathrm{ts}}$ is largest above the thermocline (Fig. 6a), where the background GS is associated with the strongest horizontal shears. The pronounced 
(a) Horizontal divergence in $10^{-6} \mathrm{~s}^{-1}$ at $228 \mathrm{~m}$ depth

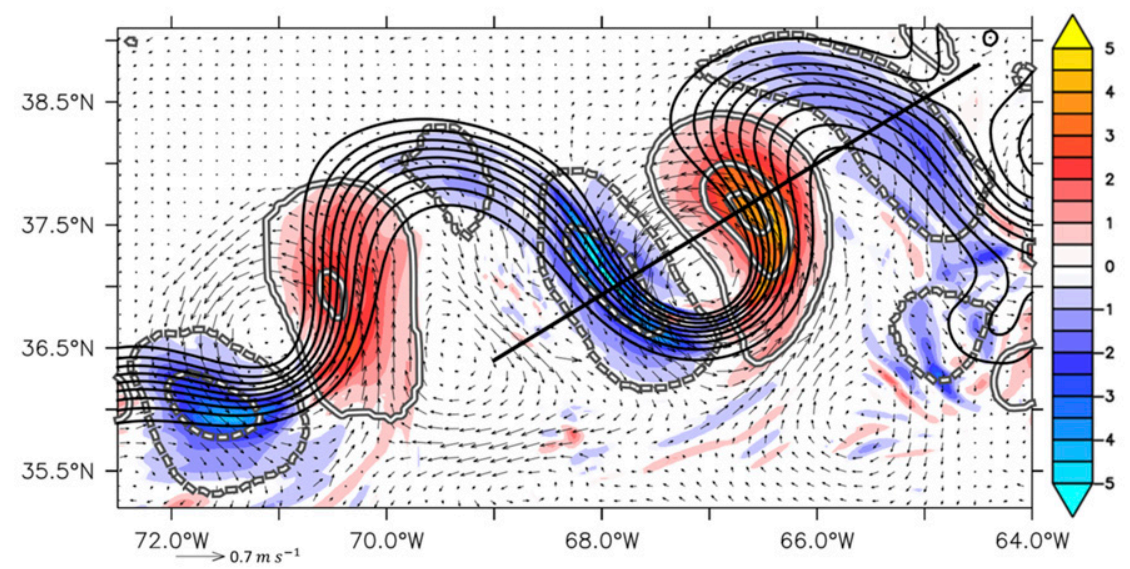

(b) Horizontal divergence in $10^{-6} \mathrm{~s}^{-1}$ at the section shown in (a)

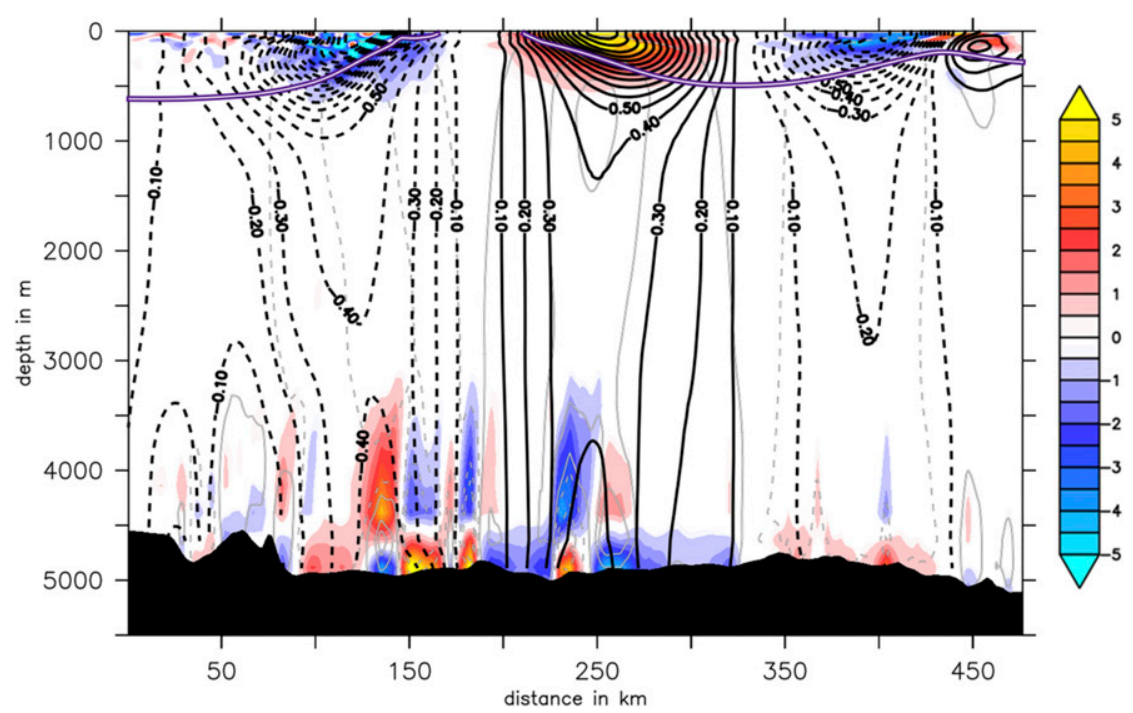

FIG. 4. (a) As in Fig. 3b, but the color shading shows the horizontal divergence $\left(10^{-6} \mathrm{~s}^{-1}\right)$ at $228-\mathrm{m}$ depth. Negative values correspond to convergence. The vertical velocity at $989-\mathrm{m}$ depth (gray-white contours; $\pm 20, \pm 100$, and $\pm 140 \mathrm{~m} \mathrm{day}^{-1}$; downward velocity contours are dashed) is shown. (b) The horizontal divergence $\left(10^{-6} \mathrm{~s}^{-1}\right)$ at the section shown in (a) with a straight line. The cross-section velocity $\left(\mathrm{m} \mathrm{s}^{-1}\right.$; black contours; contour interval is $0.1 \mathrm{~m} \mathrm{~s}^{-1}$; positive northwestward), vertical velocity (gray-white contours; $\pm 20, \pm 100$, and $\pm 140 \mathrm{~m} \mathrm{day}^{-1}$; downward velocity contours are dashed), and thermocline depth (purple-white contour; $12^{\circ} \mathrm{C}$ isotherm) are shown.

double extrema of the $\mathrm{BTI}^{\mathrm{ts}}$ (e.g., at $67.75^{\circ} \mathrm{W}$; Fig. 5) are also an artifact of the largest horizontal shears north and south of the annual-mean GS (not shown). The contribution of the Reynolds stresses to the $\mathrm{BTI}^{\mathrm{ts}}$, however, leads to a maximum energy transfer in the core of the GS (Figs. 5a and 6a). The $\mathrm{BCI}^{\mathrm{ts}}$ depends only on the anomalies of density and vertical velocity. If anomalously dense (light) water is elevated stronger than in the annual mean, the potential energy of the current increases (decreases), and if denser (lighter) water is lowered, the potential energy of the current is decreased (increased). The trough is associated with a dense water anomaly lens below the thermocline (not shown). Therefore, the strong vertical circulation within the deep cyclone-meander trough system drives an energy transfer into the eddy field in the western part, and vice versa in the eastern part. The downstream crest is associated with a light water 
(a) $\mathrm{BTI}^{t s}$ in $W m^{-3}$

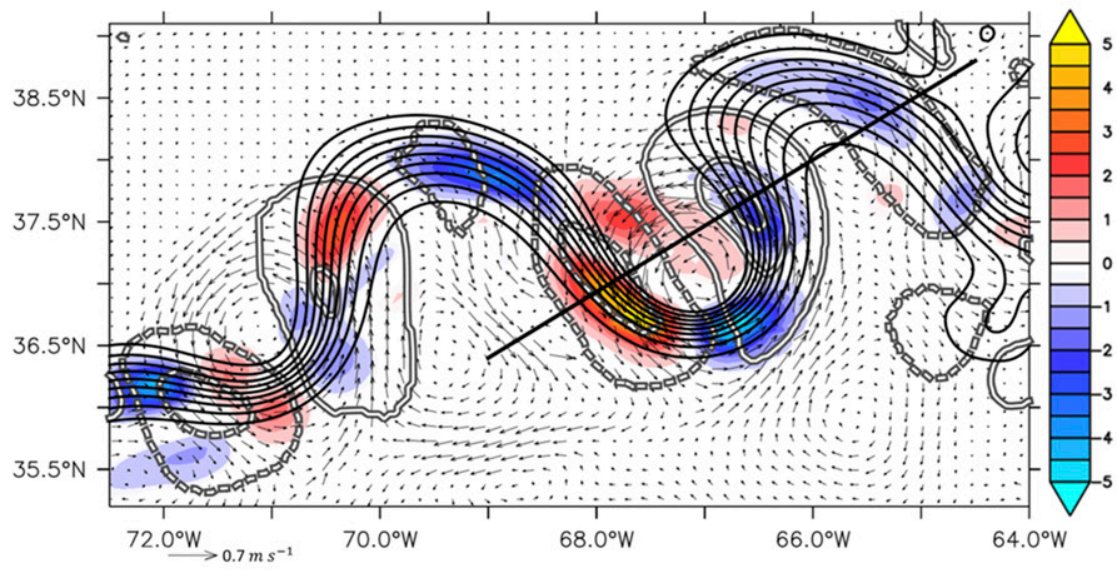

(b) $\mathrm{BCI}^{t s}$ in $\mathrm{Wm}^{-3}$

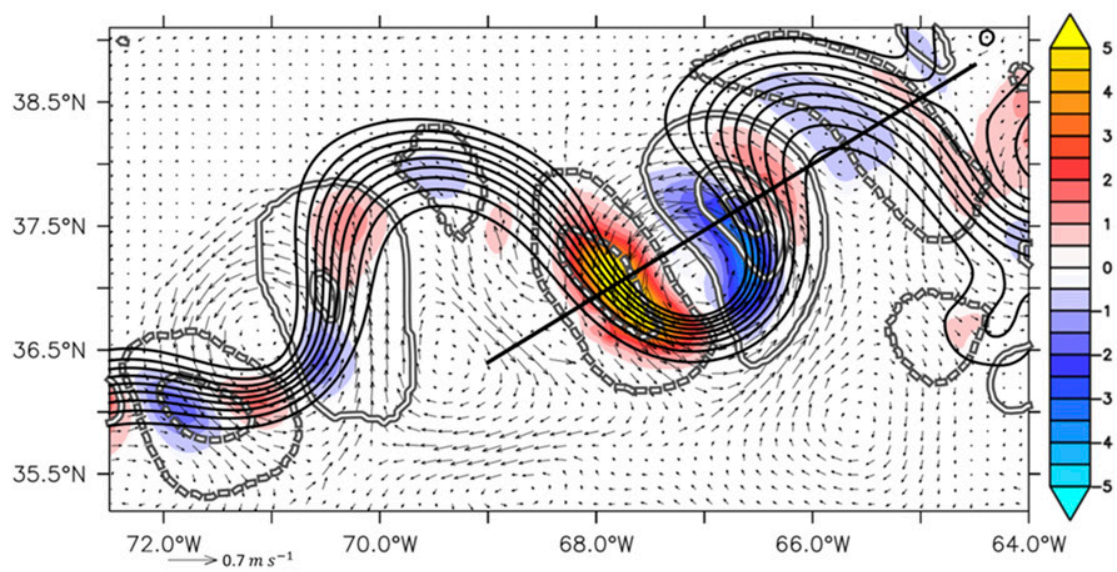

(c) $\mathrm{BTI}^{t s}+\mathrm{BCI}^{t s}$ in $W m^{-3}$

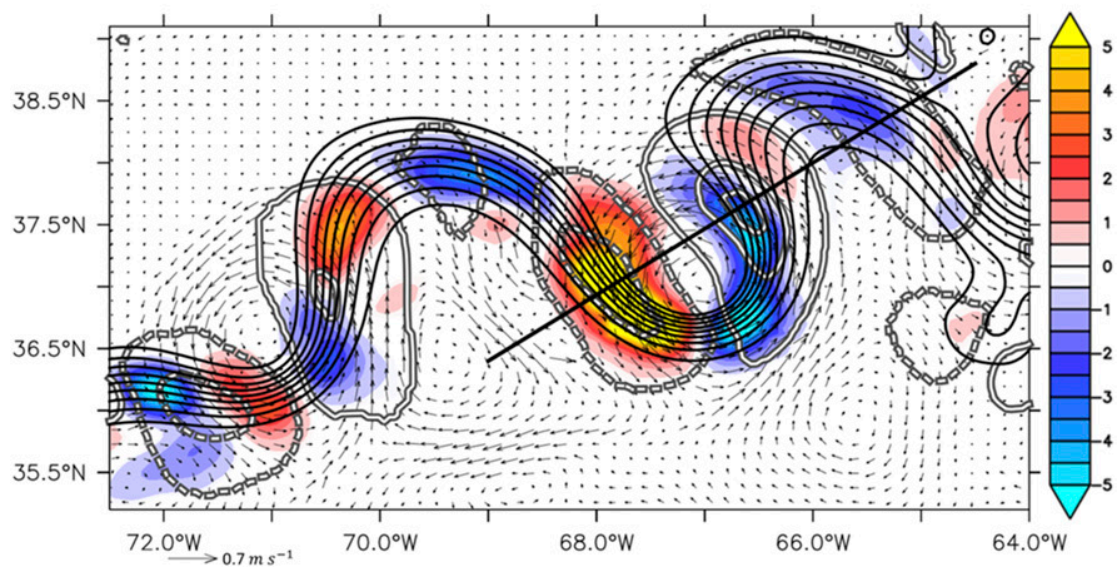

FIG. 5. As in Fig. 4a, but the color shading shows the vertically integrated energy transfers (a) $\mathrm{BTI}^{\mathrm{ts}}$, (b) $\mathrm{BCI}^{\mathrm{ts}}$, and (c) the sum of both $\left(\mathrm{W} \mathrm{m}^{-3}\right)$. 
(a) $\mathrm{BTI}^{t s}$ in $W m^{-3}$

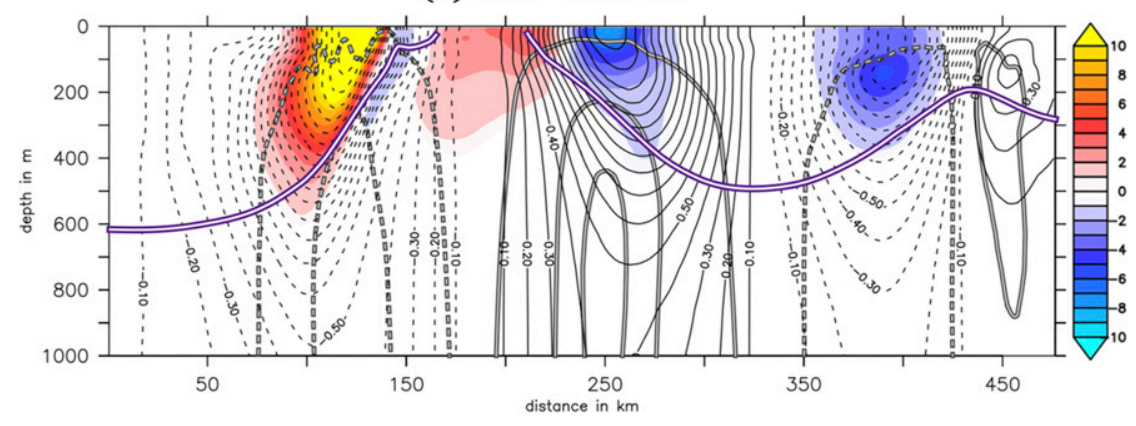

(b) $\mathrm{BCI}^{t s}$ in $W^{-3}$

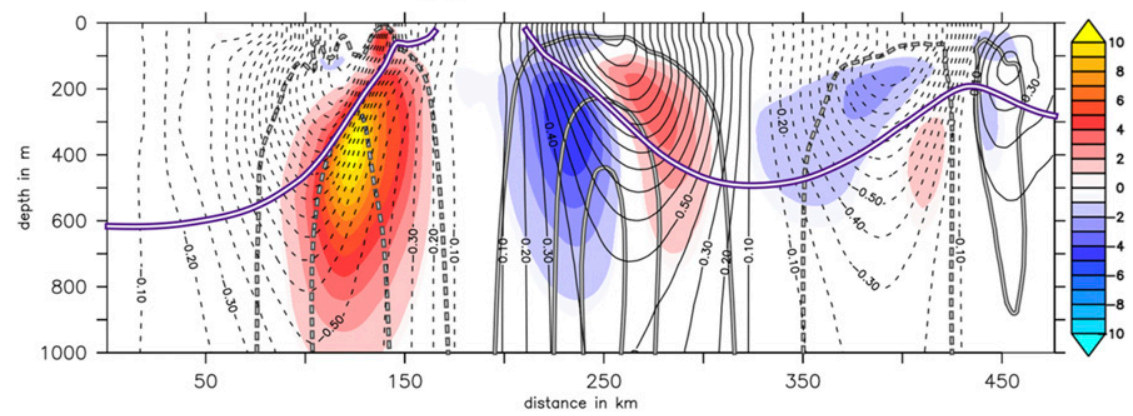

(c) $\mathrm{BTI}^{t s}+\mathrm{BCI}^{t s}$ in $W m^{-3}$

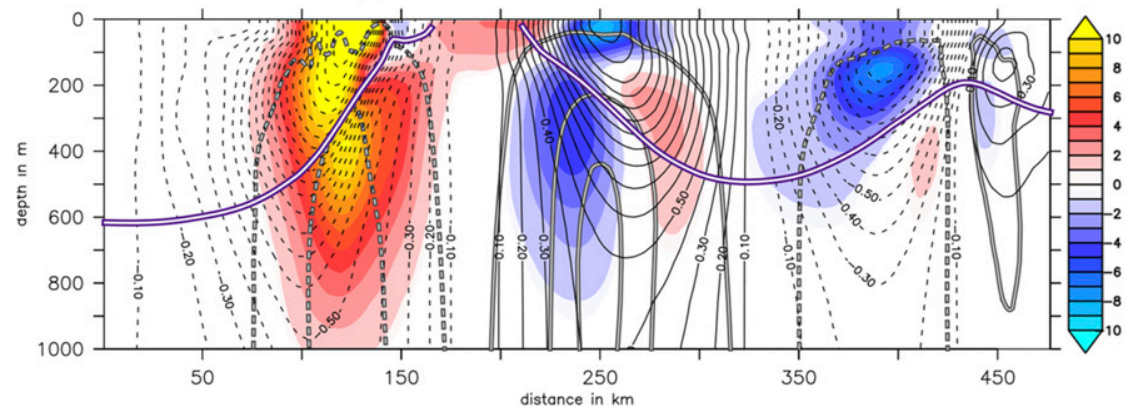

FIG. 6. As in Fig. 4b, but the color shading shows the energy transfers (a) BTI ${ }^{\text {ts }},(b)$ BCI $^{\text {ts }}$, and (c) the sum of both $\left(\mathrm{W} \mathrm{m}^{-3}\right)$.

anomaly lens above the thermocline. Therefore, the vertical circulation drives again an energy transfer into the eddy field in the western part, and vice versa in the eastern part of the meander crest. The sum of both energy transfers shows that they do not cancel each other out in the horizontal or in the vertical (Figs. $5 \mathrm{c}$ and $6 \mathrm{c}$ ). Combining both energy transfers leads to extrema of $\pm 11 \mathrm{~W} \mathrm{~m}^{-3}$ upstream and $-6 \mathrm{~W} \mathrm{~m}^{-3}$ downstream of the GS trough axis for the strong cyclogenesis event around $67^{\circ} \mathrm{W}$.

The time-evolving velocity field redistributes the density field in such a way that the lag between upperocean trough axis and deep cyclone center decreases. At the time step shown, both cyclone and anticyclone centers are more or less in phase with the meander above. Thus, the energy transfer decreases afterward, and both the meander and the cyclone are decaying while moving farther downstream. The downstreampropagating dipole pattern of the energy transfers will partly be canceled out when averaged over time. That is why we use the time mean of only the positive energy transfers into the EKE in section 6.

\section{Relating the prevalence of benthic storms with the energy transfer and the occurrence of strong increases in deep relative vorticity}

In this section, we present the vertically integrated, 30-yr-averaged EKE gain due to energy transfers for the model period 1980-2009 and relate it to the prevalence 
(a) $\left\langle\mathrm{BTI}_{+}\right\rangle$in $10^{-2} \mathrm{Wm}^{-3}$

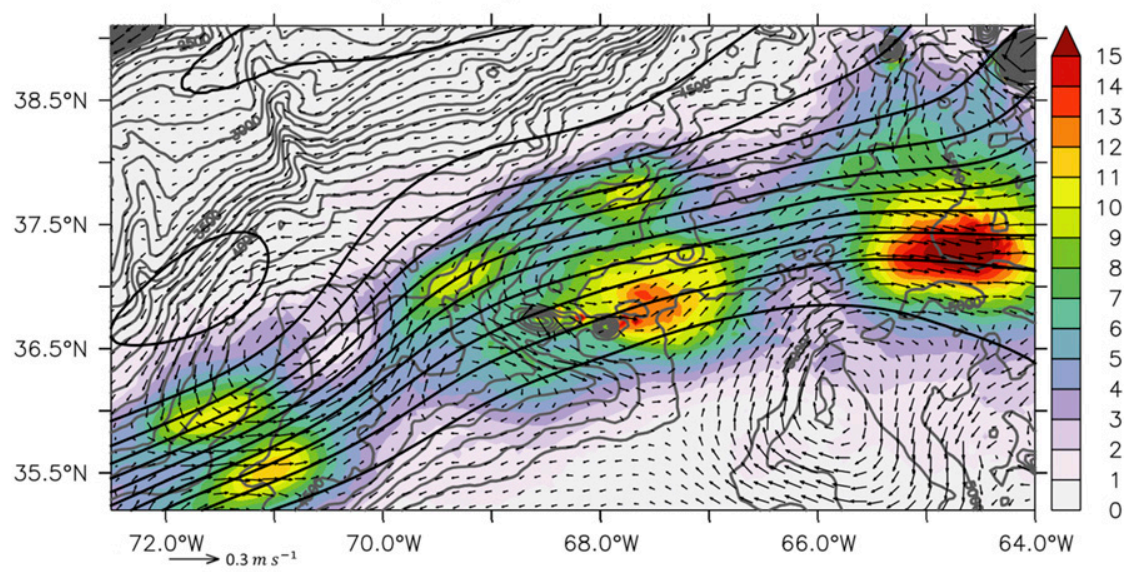

(b) $\left\langle\mathrm{BCI}_{+}\right\rangle$in $10^{-2} \mathrm{Wm}^{-3}$

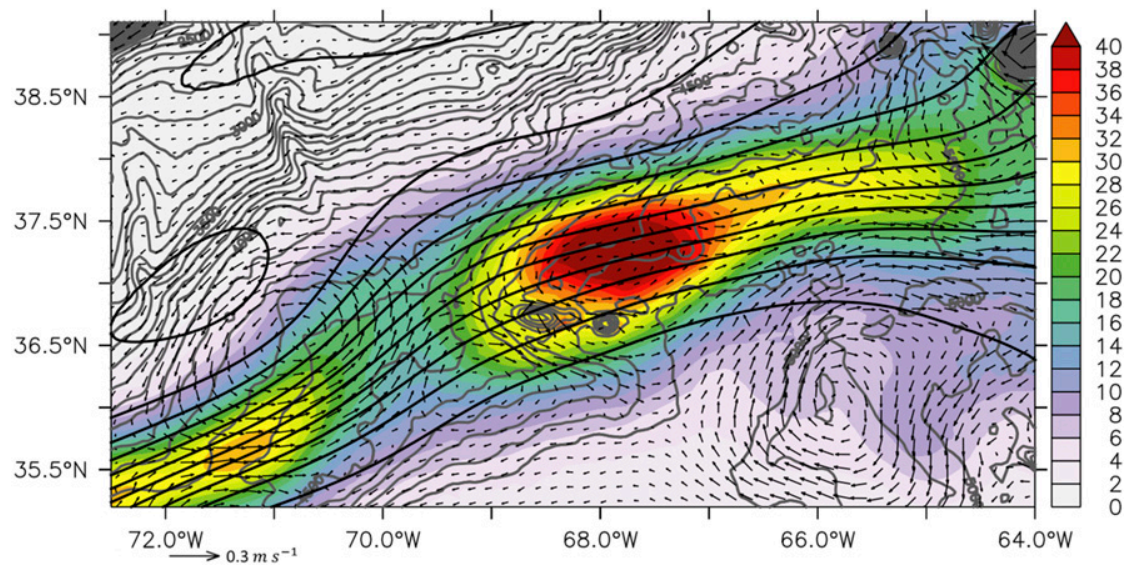

FIG. 7. The vertically integrated, 30-yr-averaged energy transfers into the EKE: (a) $\left\langle\mathrm{BTI}_{+}\right\rangle$ and (b) $\left\langle\mathrm{BCI}_{+}\right\rangle\left(10^{-2} \mathrm{~W} \mathrm{~m}^{-3}\right)$ for the model period 1980-2009. Dark gray contours show the bathymetry (contour interval is $100 \mathrm{~m}$ ), black contours show the 30 -yr-averaged sea surface height (contour interval is $0.1 \mathrm{~m}$ ), and arrows show the 30 -yr-averaged horizontal bottom velocities. The region is marked in Fig. 10.

of benthic storms shown in section 3. First, we focus on the extended SYNOP central array region, and subsequently, we extend the analysis for the whole of the domain occupied by the VIKING20 nest. Finally, we present maps of the occurrence of strong increases in deep cyclonic and anticyclonic relative vorticity as a measure for the occurrence of (anti)cyclogenesis and relate them to the benthic storm percentages and the energy transfers.

\section{a. The extended SYNOP central array region}

West of the New England Seamounts, the pattern of $\left\langle\mathrm{BTI}_{+}\right\rangle$is more or less symmetric around the GS core, as expected from the maximum horizontal shear at the flanks of the GS (Fig. 7a). Angled brackets denote the average over the period 1980-2009. In contrast, the $\left\langle\mathrm{BCI}_{+}\right\rangle$is strongest directly below the GS core due to its connection to the vertical shear of the baroclinic GS (Fig. 7b). The region of the strong, deep cyclone investigated in section 5 (the region of the SYNOP measurements) is associated with two maxima of $\left\langle\mathrm{BTI}_{+}\right\rangle$of up to $12 \times 10^{-2} \mathrm{~W} \mathrm{~m}^{-3}$ around $67.5^{\circ} \mathrm{W}$ and a very strong $\left\langle\mathrm{BCI}_{+}\right\rangle$of more than $40 \times 10^{-2} \mathrm{~W} \mathrm{~m}^{-3}$ around $68^{\circ} \mathrm{W}$. This confirms the activity of strong mixed barotropic-baroclinic instability in this region. Further, the region is associated with a high benthic storm percentage of more than $10 \%$ for the condition $\left|\mathbf{u}_{h, \mathrm{btm}}\right|^{\prime}>0.1 \mathrm{~m} \mathrm{~s}^{-1}$ (Fig. 8a). The area of high benthic storm percentage is located below the maximum of the combined energy transfer and farther downstream 


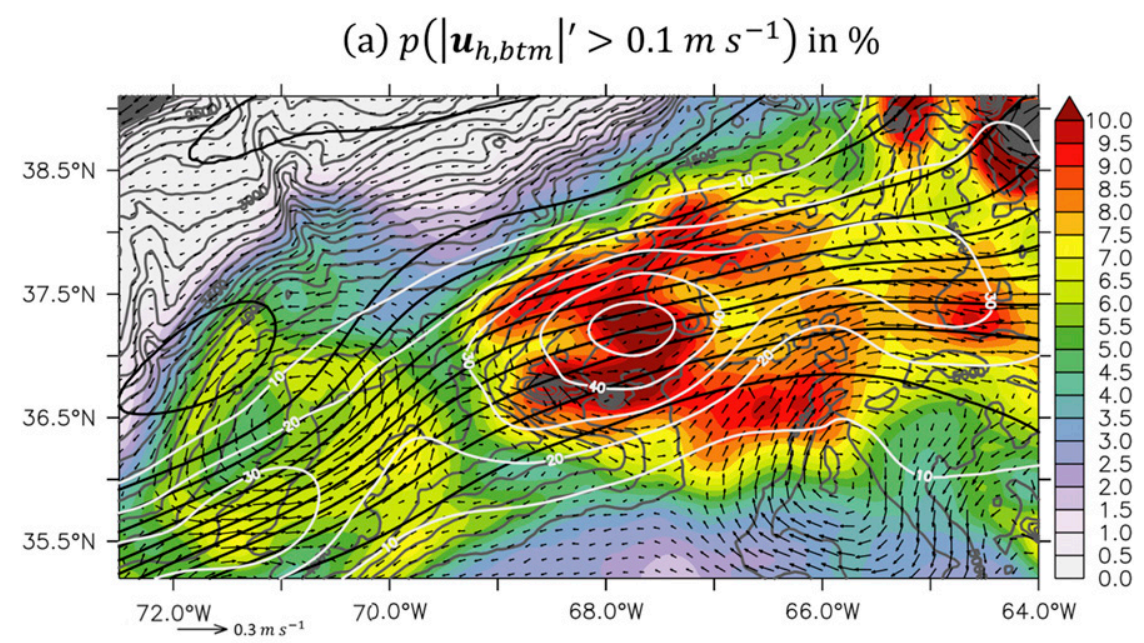

(b) $\left\langle\mathrm{EKE}_{b t m}\right\rangle$ in $J m^{-3}$

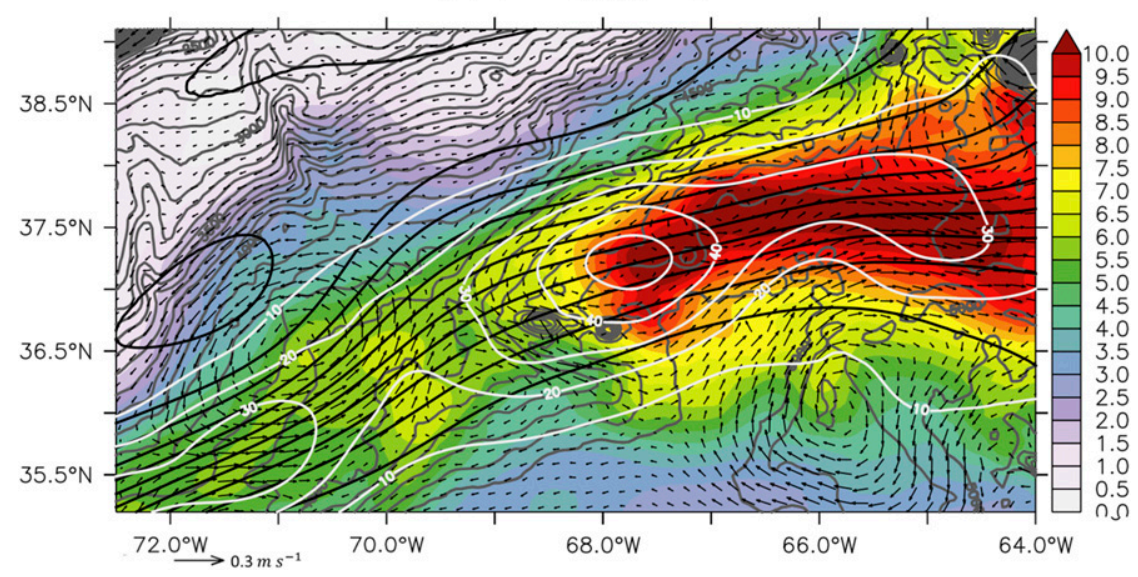

FIG. 8. As in Fig. 7, but the color shading shows (a) the percentage that the near-bottom absolute velocity exceeds its local annual mean by at least $0.1 \mathrm{~m} \mathrm{~s}^{-1}$ and (b) the 30 -yr-averaged near-bottom EKE for the model period 1980-2009. The percentage is derived from 5-day mean model output. Thick white contours show the sum of the energy transfers $\left(10^{-2} \mathrm{~W} \mathrm{~m}^{-3}\right)$ shown in Fig. 7.

At around $64.5^{\circ} \mathrm{W}$, a further $\left\langle\mathrm{BTI}_{+}\right\rangle$maximum is found. Its origin might be connected to the influence of the New England Seamounts on the GS and the deep cyclones.

Upstream, around $71^{\circ} \mathrm{W}$, a second pair of strong meander trough and deep cyclone is seen in the case study (Fig. 5). Both structures also appear in the 30-yr average (Fig. 7). Mixed barotropic-baroclinic instability associated with cyclogenesis occurs in this region so often that the trough and the deep cyclone strongly contribute to the MKE. Consistent with Fig. 5, the energy transfers are strongest in the upstream part of the meander trough. However, the presence of a meander trough and deep cyclone in the annual means (not shown), and also in the 30 -yr average, leads to relatively small amplitudes of the energy transfers, compared to regions of more-or-less parallel background flow. Consistently, the benthic storm percentage of occurrence and nearbottom EKE increase along the GS path are smaller in the region around $71^{\circ} \mathrm{W}$ than in the region around $68^{\circ} \mathrm{W}$. The presence of both annual-mean meander troughs and annual-mean deep cyclones is a clear indicator for frequent cyclogenesis. For such regions, energy transfer is a less important indicator. Note that in contrast to the simulation, in the region around $68^{\circ} \mathrm{W}$, a time-mean meander trough was found by Cronin (1996), Lee and Cornillon (1996), and Thompson and Schmitz (1989). However, their averaging periods were 2, 8, and 3 years, respectively. Cronin (1996) and 
(a) $\left\langle\mathrm{BTI}_{+}\right\rangle$in $\mathrm{Wm}^{-3}$

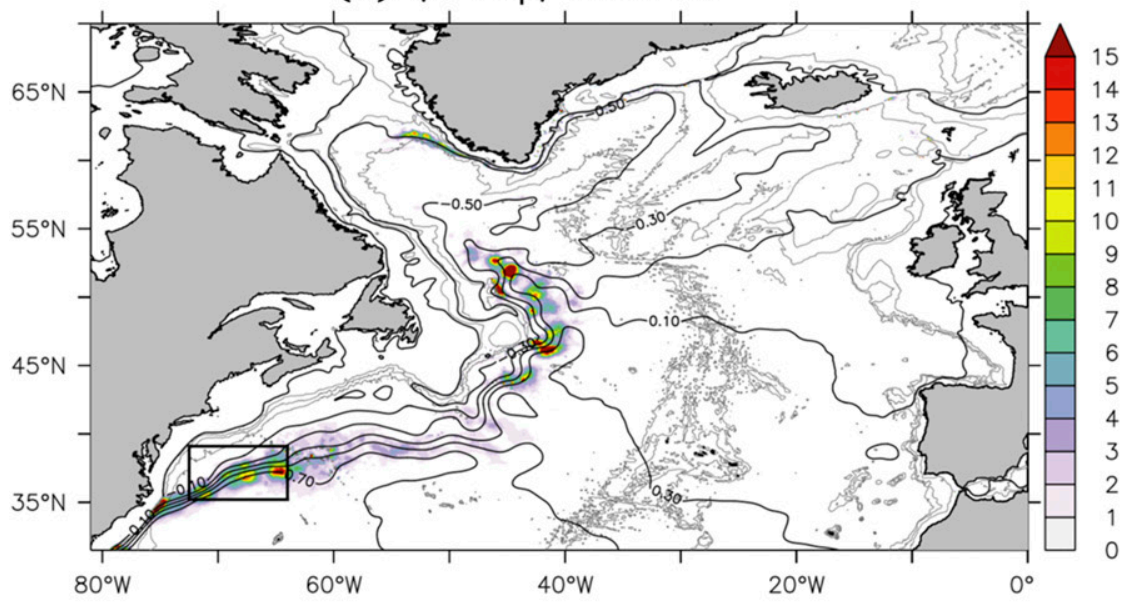

(b) $\left\langle\mathrm{BCI}_{+}\right\rangle$in $\mathrm{Wm}^{-3}$

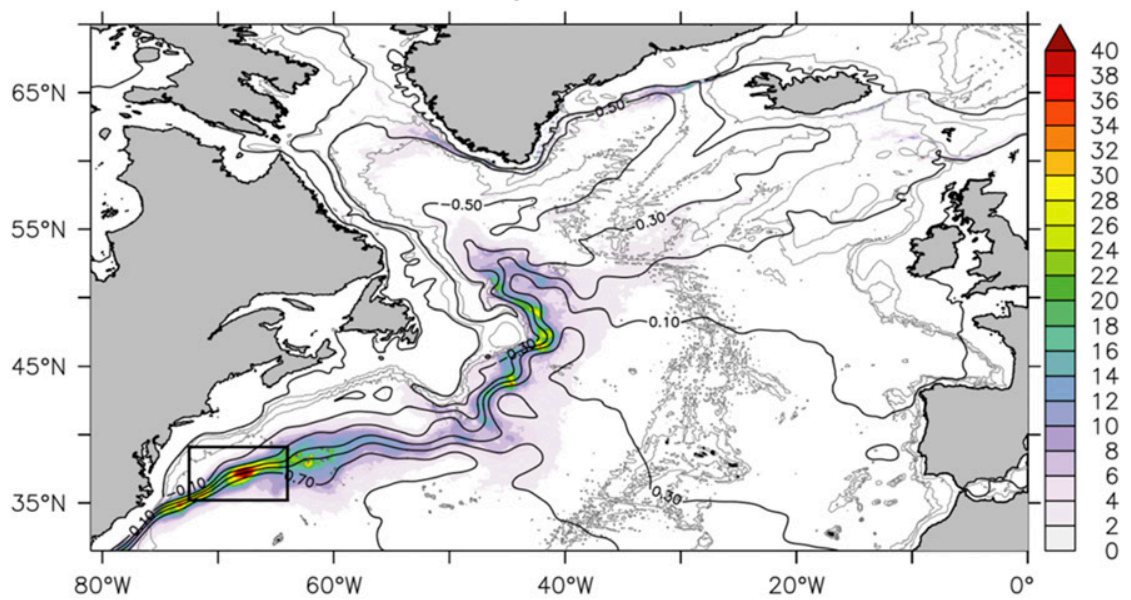

(c) $\left\langle\mathrm{BTI}_{+}\right\rangle+\left\langle\mathrm{BCI}_{+}\right\rangle$in $\mathrm{Wm}^{-3}$

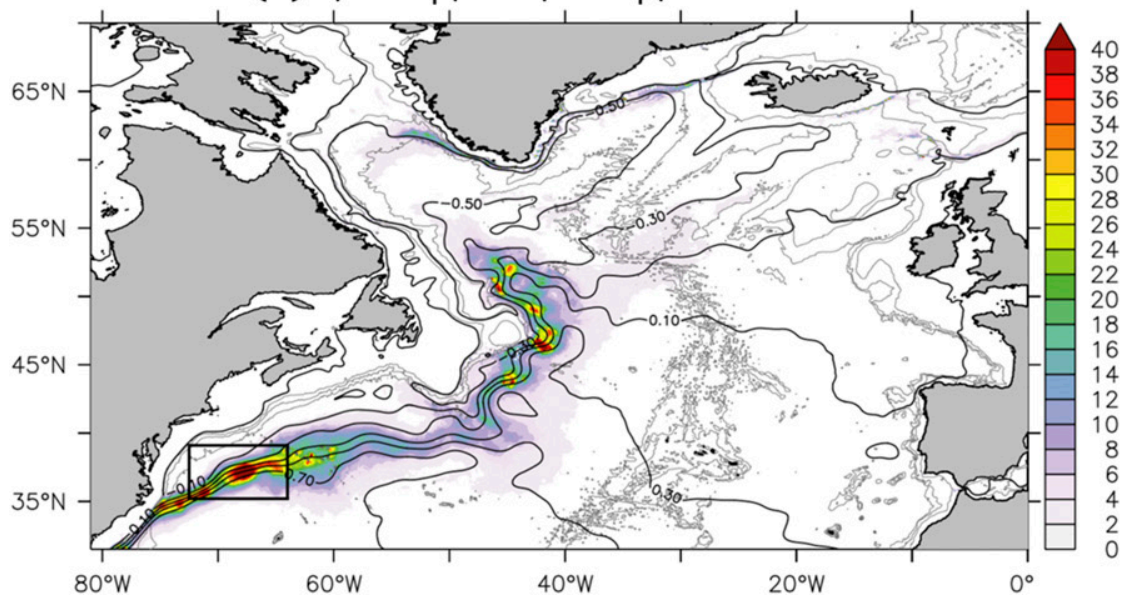

FIG. 9. As in Fig. 1, but the color shading shows the vertically integrated, 30-yr-averaged energy transfers (a) $\left\langle\mathrm{BTI}_{+}\right\rangle$, (b) $\left\langle\mathrm{BCI}_{+}\right\rangle$, and (c) the sum of both $\left(10^{-2} \mathrm{~W} \mathrm{~m}^{-3}\right)$ for the model period 1980-2009. 
Thompson and Schmitz (1989) also consistently found a time-mean deep cyclone below the trough.

The difference between both cyclogenesis regions can be attributed to the underlying topography. Sutyrin et al. (2001) showed in an idealized model study that cross-stream bottom slopes in the same direction as the isopycnal tilt (which is the case between the separation point of the GS at Cape Hatteras and $69.5^{\circ} \mathrm{W}$ ) limit the meander growth of the GS. Considering the mechanism of baroclinic instability of Phillips (1951), this can be explained by the reduced squeezing or stretching of the lower column, when the topography slopes in the same direction as the interface. The bottom slope in the cross-stream direction decreases from west to east. Sutyrin et al. (2001) demonstrated that the pinch off of warm- and cold-core rings from strong meanders is inhibited by even the smallest slopes at $70^{\circ} \mathrm{W}$. At $69.5^{\circ} \mathrm{W}$, the Gulf Stream leaves the slope and flows above the largest downward gradients of the topography. Just downstream of this topographic slope, a strong gain in EKE due to instabilities occurs, with the largest increase in near-bottom EKE and the region of highest benthic storm probabilities. Thus, the results are consistent with those of Sutyrin et al. (2001); in particular, the instabilities are only able to fully develop when the current leaves the slope. However, between $72.0^{\circ}$ and $69.5^{\circ} \mathrm{W}$, the simulated GS flows above a plateau of very small slopes. In this region, meanders and deep cyclones are able to develop. Nevertheless, the topography confines the action of cyclogenesis in this region much more than east of $69.5^{\circ} \mathrm{W}$. Thus, in the western region, the deep cyclones develop more or less in the same region, and for each year, the annual-mean cyclone is associated with higher annual mean velocities, compared to the eastern annual-mean cyclone. The region around $71^{\circ} \mathrm{W}$ is consequently associated with much lower probabilities for the condition $\left|\mathbf{u}_{h, \mathrm{btm}}\right|^{\prime}>$ $0.1 \mathrm{~m} \mathrm{~s}^{-1}$ and much lower energy transfers.

\section{b. The North Atlantic}

In the simulated North Atlantic, high values of $\left\langle\mathrm{BTI}_{+}\right\rangle$and $\left\langle\mathrm{BCI}_{+}\right\rangle$occur in the GS-NAC system and in the West Greenland Current (Fig. 9). Furthermore, the overflow regions in the Denmark Strait, IcelandScotland Ridge, and Faroe Bank Channel are associated with enhanced $\left\langle\mathrm{BCI}_{+}\right\rangle$. Most regions of high energy transfer are associated with high near-bottom EKE and high benthic storm probability (Fig. 2), indicating the importance of instabilities in driving benthic storms. Previous studies addressed the strong barotropic instability of the West Greenland Current (Eden and Böning 2002) and the dominant influence of the baroclinic instability in the Denmark Strait Overflow
(Smith 1976; Jungclaus et al. 2001), as well as in the Faroe Bank Channel Overflow (Geyer et al. 2006; Guo et al. 2014). In both overflow regions, intense cyclogenesis with the meandering current below and circular movements above has been found (Jungclaus et al. 2001; Geyer et al. 2006).

In the GS-NAC system, the $\left\langle\mathrm{BCI}_{+}\right\rangle$is found to be, in general, larger than the $\left\langle\mathrm{BTI}_{+}\right\rangle$. Highest energy transfers for both routes occur in the NAC around Flemish Cap and in the GS west of the New England Seamounts. The time-mean NAC around Flemish Cap is associated with four meander troughs: south, east, northeast, and north of Flemish Cap. For both energy transfers, maxima are found in the upstream half of these troughs. This is also true for the time-mean trough of the Gulf Stream around $71^{\circ} \mathrm{W}$. The existence of the time-mean meander troughs, as well as the strong energy transfers into the EKE, indicates strong activity of mixed barotropic-baroclinic instability in these regions. The region of the SYNOP central array is special: the GS does not show a time-mean meander trough in this region, and it is associated with by far the strongest $\left\langle\mathrm{BCI}_{+}\right\rangle$in the North Atlantic and a maximum in $\left\langle\mathrm{BTI}_{+}\right\rangle$. As discussed above, the energy transfers are reduced when, at a specific location, meander troughs form so often that they imprint into the MKE. This is not the case for the SYNOP region in our model, and thus, the energy transfers can get very large. The regions of strong energy transfers-the SYNOP region as well as the time-mean meander troughs in the NAC and the GS (Fig. 7c) - are collocated with maxima in near-bottom EKE and benthic storm percentage (Fig. 2), indicating that mixed barotropicbaroclinic instability is an important driver of benthic storms below the GS-NAC system. Between the New England Seamounts and the Newfoundland Rise, moderate energy transfers, near-bottom EKE, and benthic storm percentages are found. This suggests that mixed barotropic-baroclinic instability is driving benthic storms also in this region-consistent with the results of Bower and Hogg (1996) — but is relatively rare for each specific location.

Cyclogenesis is an inherent part of the mixed barotropic-baroclinic instability of a baroclinic jet and the mechanism that explains the collocation of strong energy transfers into the EKE, near-bottom EKE, and frequent benthic storms. To underpin this, we identify the percentage that the 5-day mean relative vorticity $\zeta=v_{x}-u_{y}$ at 2054-m depth is positive (cyclonic) and its subsequent 5-day mean is more than $0.02 f$ larger as an indicator for cyclogenesis. Here, $f=2 \Omega \sin \varphi$ is the planetary vorticity with the rotation rate of the Earth $\Omega=7.2921 \times 10^{-5} \mathrm{rads}^{-1}$ and the latitude $\varphi$. 
(a) $p\left(\zeta^{t s}>0\right.$ and $\left.\zeta^{t s+1}>\zeta^{t s}+0.02 f\right)$ in $\%$

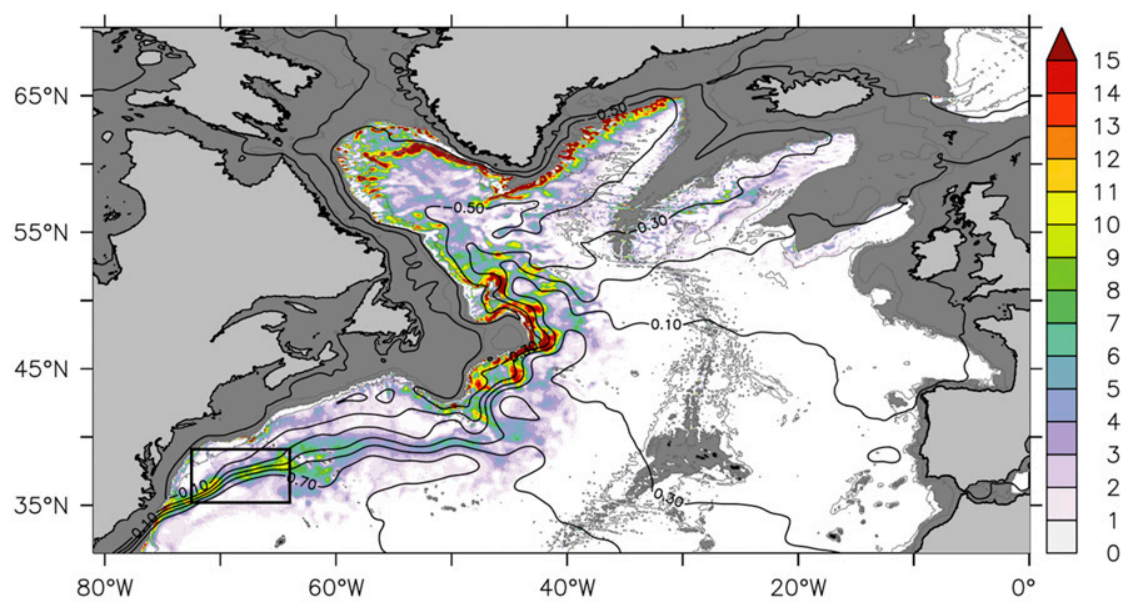

(b) $p\left(\zeta^{t s}<0\right.$ and $\left.\zeta^{t s+1}<\zeta^{t s}-0.02 f\right)$ in $\%$

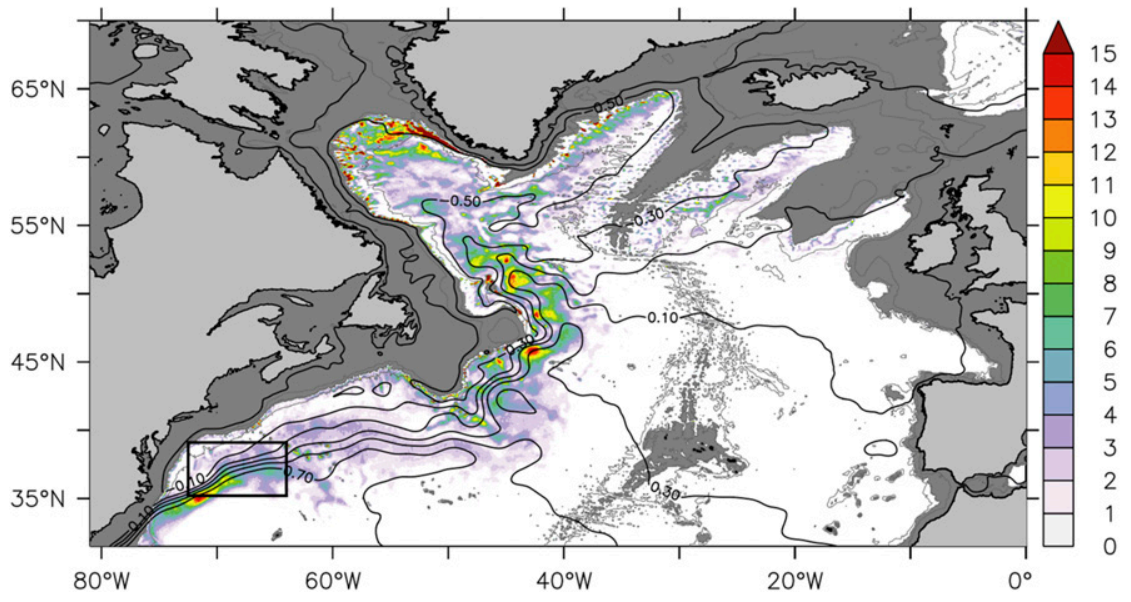

FIG. 10. As in Fig. 1, but the color shading shows the percentage that the 5-day mean relative vorticity at 2054-m depth is (a) positive (cyclonic) and its subsequent 5-day mean value is more than $0.02 f$ larger and (b) negative (anticyclonic) and its subsequent 5-day mean is more than $0.02 f$ smaller.

Strong increases in deep cyclonic relative vorticity occur in the model below the whole GS-NAC system, as well as in the Labrador Sea and at the East Greenland slope (Fig. 10a). In accordance with the occurrence of benthic storms (Fig. 2a), the near-bottom EKE (Fig. 2b), and the energy transfer (Fig. 9c), enhanced percentages are found for the time-mean troughs of the NAC around Flemish Cap, for the Gulf Stream around $71^{\circ} \mathrm{W}$, and for the SYNOP region and moderate percentages for the GS between the New England Seamounts and the Newfoundland Rise. This gives strong indication that in the GS-NAC system, the connecting mechanism between upper-ocean energy transfer and benthic storms is cyclogenesis.
Analogously, we identify the percentage that $\zeta$ is negative (anticyclonic) and its subsequent 5-day mean is more than $0.02 f$ more negative as an indicator for anticyclogenesis. The percentages for a strong increase in deep anticyclonic relative vorticity are smaller than for cyclonic relative vorticity (Fig. 10b). Between the New England Seamounts and the Grand Banks, strong increases in deep anticyclonic relative vorticity occur very rarely in the model. Percentages of more than $10 \%$ are found for the Gulf Stream west of $70^{\circ} \mathrm{W}$, for the time-mean meander crests of the NAC, and in the Northern Labrador Sea. Except for the latter, the regions of these maxima are associated with only small benthic storm percentages (Fig. 2a), indicating that 
anticyclogenesis plays a minor role in driving benthic storms below the GS-NAC system. This is consistent with the results of the SYNOP measurements and can be attributed, at least partly, to the net divergence due to the centripetal acceleration that weakens anticyclones and strengthens cyclones (Kämpf 2005).

In the Labrador Sea, as well as at the East Greenland slope, the 5-day mean model output does not adequately capture the variability of single eddies due to their smaller size because of the smaller Rossby radius of deformation. Therefore, the percentages for strong increases in (anti)cyclonic relative vorticity are difficult to interpret in terms of (anti)cyclogenesis in these regions. The enhanced percentages in the Labrador Seaunder are probably due to the propagation of the West Greenland eddies and not due to (anti)cyclogenesis. To clarify this, a higher sampling frequency is needed.

\section{Conclusions and discussion}

In this study, we present strong indication that mixed barotropic-baroclinic instability accompanied by cyclogenesis is a major driver of benthic storms below the Gulf Stream (GS) and the North Atlantic Current (NAC). Using 30 years of output from a high-resolution model of the North Atlantic, it is found that most of the benthic storms in the model occur near the western boundary in association with the GS-NAC system. In the late 1980s and the early 1990s, mesoscale-resolving mooring arrays were deployed as part of the Synoptic Ocean Prediction Experiment (SYNOP) in selected regions of the separated GS. The measurements revealed that the development of GS meander troughs is accompanied by the genesis of deep cyclones with near-bottom velocities of up to more than $0.5 \mathrm{~m} \mathrm{~s}^{-1}$ (Savidge and Bane 1999a). The investigation of one of these events in the simulation demonstrates that the model used here reproduces the cyclogenesis mechanism and properties observed in the SYNOP experiment. The analysis of the energy transfer into the eddy kinetic energy during the event shows the importance of both baroclinic and barotropic instability, with energy being extracted from the jet in the upstream part of the meander trough and partly returned to the jet in the downstream part of the meander trough. This motivates us to use the 30-yr time mean of the eddy kinetic energy gain due to energy transfers from the (annual mean) background flow as an indicator for mixed barotropic-baroclinic instability-driven cyclogenesis. As a further indicator for the genesis of deep cyclones and anticyclones, we examine the frequency of strong local increases in deep (anti)cyclonic relative vorticity.
The time-mean eddy kinetic energy gain due to energy transfer, as well as the frequency of strong increases in deep cyclonic vorticity, is found to be collocated well with the regions in which benthic storms occur most frequently. This suggests an important role for mixed barotropic-baroclinic instability-driven cyclogenesis in generating benthic storms throughout the model simulation. The GS between Cape Hatteras and the New England Seamounts and the NAC near Flemish Cap are found to be the regions of largest energy transfer and most frequent benthic storms. Large increases in deep anticyclonic relative vorticity occur less often than large increases in cyclonic vorticity in the simulation. Moreover, regions of frequent large increases in deep anticyclonic relative vorticity are found to not be associated with frequent benthic storms. This indicates that anticyclogenesis plays a minor role in driving benthic storms below the GS-NAC system. A quantitative analysis on which part of the deep flow is (anti)cyclogenesis driven, as well as an investigation of the contribution of (anti)cyclogenesis to bottom energy dissipation, sediment transport, and surface deep ocean exchange, could be the object of future research.

In regions of very frequent cyclogenesis, the meander troughs and deep cyclones contribute strongly to the annual mean flow. The nonparallel background flow leads to relatively small energy transfers, while the benthic storm percentages are still high. In such regions, the coexistence of time-mean meander troughs and time-mean deep cyclones, as well as frequent large increases in deep cyclonic relative vorticity, are better indicators for frequent cyclogenesis than the energy transfer into the eddy field.

The pattern of the percentages for the simulated VIKING20 bottom currents to exceed $0.2 \mathrm{~m} \mathrm{~s}^{-1}$ provides an orientation for the design of deep ocean measurements. The percentages are of the same order as the observed and simulated probabilities noted by Cronin et al. (2013) for the greater Agulhas region. They are larger than $50 \%$ for the coherent bottom currents, such as the DWBC along the coast. Below the core of the GS-NAC system, percentages of $10 \%-30 \%$ are found, while such large velocities occur very rarely away from strong near-surface currents. The model used by Cronin et al. (2013) and VIKING20 have about the same vertical resolution in the deep ocean, and both use a partial-cell approach for the bottom cell and a similar bottom friction parameterization. The validation of Cronin et al. (2013) shows widespread agreement between the simulation and observation. Differences might be attributable to the coarse vertical resolution of the model in the deep ocean. 
Eddy-mean energy transfers in the western North Atlantic derived from ocean general circulation model studies were recently presented by von Storch et al. (2012), Zhai and Marshall (2013), Chen et al. (2014), and Kang and Curchitser (2015). All of these studies indicate that the energy transfer is very strong west of the New England Seamounts, in agreement with our results. The spatial pattern of the EKE gain due to energy transfers presented here is similar to the one obtained by the model simulations of Kang and Curchitser (2015). Further, the pattern of the Reynolds stresses (not shown) is similar to the one obtained from satellite measurements presented by Ducet and Le Traon (2001) and Greatbatch et al. (2010b). Strong energy transfers toward the EKE, respective strong Reynolds stresses, are found around $68^{\circ}$ and $71^{\circ} \mathrm{W}$. Here, we show that these energy transfers are associated with the prevalence of benthic storms.

Unrepresented ocean-atmosphere feedbacks remain an important deficit of OGCMs. Ma et al. (2016) showed that the feedback between ocean mesoscale eddies and the atmosphere via surface turbulent heat fluxes fundamentally controls the energy budget of the Kuroshio by comparing two high-resolution coupled model simulations. The feedback leads to much stronger EPE dissipation, less energy transfer between EPE and EKE, less EKE, and larger MKE. A similar reduction in EKE and an increase in MKE are also found for the Gulf Stream in their study. Thus, ocean general circulation models might overestimate the strength of the deep cyclones.

Results of this study for the Northwest Corner should be treated with care, since the simulated Northwest Corner extends too far northwest (Breckenfelder et al. 2017). However, a velocity section through the NAC at $47^{\circ} \mathrm{N}$ derived from measurements of six ship cruises showed very good agreement with the timemean model solution (Mertens et al. 2014). Andres et al. (2016) found evidence for interactions between deep cyclones and the deep western boundary current at the Mid-Atlantic Bight. Such interactions presumably do also occur east of Flemish Cap and need future research. A further developed VIKING20 with a properly simulated Northwest Corner will be a promising candidate for that.

Acknowledgments. The model computations and data analysis were performed at the North German Supercomputing Alliance (HLRN). Erik Behrens implemented the model and performed the experiment. The study was supported by the cooperative program "RACE-Regional Atlantic Circulation and Global Change" (BMBF Grant 03F0729C). The authors wish to thank the DRAKKAR group for their continuous support in the model development. This is PMEL contribution 4655 .

\section{REFERENCES}

Andres, M., 2016: On the recent destabilization of the Gulf Stream path downstream of Cape Hatteras. Geophys. Res. Lett., 43, 9836-9842, https://doi.org/10.1002/2016GL069966.

_ J. Toole, D. Torres, W. Smethie, T. Joyce, and R. Curry, 2016: Stirring by deep cyclones and the evolution of Denmark Strait Overflow Water observed at line W. Deep-Sea Res., 109, 1026, https://doi.org/10.1016/j.dsr.2015.12.011.

Arakawa, A., and V. R. Lamb, 1977: Computational design of the basic dynamical processes of the UCLA general circulation model. Methods in Computational Physics, J. Chang, Ed., Vol. 17, Academic Press, 173-265, https://doi.org/10.1016/B9780-12-460817-7.50009-4.

Arbic, B. K., and Coauthors, 2009: Estimates of bottom flows and bottom boundary layer dissipation of the oceanic general circulation from global high-resolution models. J. Geophys. Res., 114, C02024, https://doi.org/10.1029/2008JC005072.

Barnier, B., and Coauthors, 2006: Impact of partial steps and momentum advection schemes in a global ocean circulation model at eddy-permitting resolution. Ocean Dyn., 56, 543567, https://doi.org/10.1007/s10236-006-0082-1.

, and Coauthors, 2007: Eddy-permitting ocean circulation hindcasts of the past decades. CLIVAR Exchanges, No. 3, International CLIVAR Project Office, Southampton, United Kingdom, 8-10.

Behrens, E., 2013: The oceanic response to Greenland melting: The effect of increasing model resolution. Ph.D. thesis, ChristianAlbrechts-Universität, 166 pp.

Blanke, B., and P. Delecluse, 1993: Variability of the tropical Atlantic Ocean simulated by a general circulation model with two different mixed-layer physics. J. Phys. Oceanogr., 23, 1363-1388, https://doi.org/10.1175/1520-0485(1993)023<1363: VOTTAO $>2.0 . \mathrm{CO} ; 2$.

Böning, C. W., E. Behrens, A. Biastoch, K. Getzlaff, and J. L. Bamber, 2016: Emerging impact of Greenland meltwater on deepwater formation in the North Atlantic Ocean. Nat. Geosci., 9, 523-527, https://doi.org/10.1038/ngeo2740.

Bower, A. S., and T. Rossby, 1989: Evidence of cross-frontal exchange processes in the Gulf Stream based on isopycnal RAFOS float data. J. Phys. Oceanogr., 19, 1177-1190, https:// doi.org/10.1175/1520-0485(1989)019<1177:EOCFEP>2.0.CO;2. , and N. G. Hogg, 1992: Evidence for barotropic wave radiation from the Gulf Stream. J. Phys. Oceanogr., 22, 42-61, https://doi.org/10.1175/1520-0485(1992)022<0042: EFBWRF $>2.0 . \mathrm{CO} ; 2$.

— circulations at $55^{\circ} \mathrm{W}$. J. Phys. Oceanogr., 26, 1002-1022, https://doi.org/10.1175/1520-0485(1996)026<1002:SOTGSA> 2.0.CO;2.

Breckenfelder, T., M. Rhein, A. Roessler, C. W. Böning, A. Biastoch, E. Behrens, and C. Mertens, 2017: Flow paths and variability of the North Atlantic Current: A comparison of observations and a high-resolution model. J. Geophys. Res. Oceans, 122, 2686-2708, https://doi.org/10.1002/2016JC012444.

Charney, J. G., 1947: The dynamics of long waves in a baroclinic westerly current. J. Meteor., 4, 136-162, https://doi.org/10.1175/ 1520-0469(1947)004<0136:TDOLWI>2.0.CO;2. 
Chelton, D. B., R. A. deSzoeke, M. G. Schlax, K. El Naggar, and N. Siwertz, 1998: Geographical variability of the first baroclinic Rossby radius of deformation. J. Phys. Oceanogr., 28, 433-460, https://doi.org/10.1175/1520-0485(1998)028<0433: GVOTFB $>2.0 . C O ; 2$.

Chen, R., G. R. Flierl, and C. Wunsch, 2014: A description of local and nonlocal eddy-mean flow interaction in a global eddypermitting state estimate. J. Phys. Oceanogr., 44, 2336-2352, https://doi.org/10.1175/JPO-D-14-0009.1.

Cronin, M., 1996: Eddy-mean flow interaction in the Gulf Stream at $68^{\circ} \mathrm{W}$. Part II: Eddy forcing on the time-mean flow. J. Phys. Oceanogr., 26, 2132-2151, https://doi.org/10.1175/ 1520-0485(1996)026<2132:EMFIIT>2.0.CO;2.

— Gulf Stream at $68^{\circ} \mathrm{W}$. Part I: Eddy energetics. J. Phys. Oceanogr., 26, 2107-2131, https://doi.org/10.1175/1520-0485(1996) 026<2107:EFIITG > 2.0.CO;2.

, T. Tozuka, A. Biastoch, J. V. Durgadoo, and L. M. Beal, 2013: Prevalence of strong bottom currents in the greater Agulhas system. Geophys. Res. Lett., 40, 1772-1776, https:// doi.org/10.1002/grl.50400.

Cushman-Roisin, B., 1994: Introduction to Geophysical Fluid Dynamics. Prentice-Hall, 320 pp.

Debreu, L., C. Vouland, and E. Blayo, 2008: AGRIF: Adaptive grid refinement in Fortran. Comput. Geosci., 34, 8-13, https:// doi.org/10.1016/j.cageo.2007.01.009.

Donohue, K. A., D. R. Watts, K. L. Tracey, A. D. Greene, and M. Kennelly, 2010: Mapping circulation in the Kuroshio Extension with an array of current and pressure recording inverted echo sounders. J. Atmos. Oceanic Technol., 27, 507527, https://doi.org/10.1175/2009JTECHO686.1.

Ducet, N., and P.-Y. Le Traon, 2001: A comparison of surface eddy kinetic energy and Reynolds stresses in the Gulf Stream and the Kuroshio Current systems from merged TOPEX/Poseidon and ERS-1/2 altimetric data. J. Geophys. Res., 106, 16603-16 622, https://doi.org/10.1029/2000JC000205.

Eady, E. T., 1949: Long waves and cyclone waves. Tellus, 1 (3), 33-52, https://doi.org/10.3402/tellusa.v1i3.8507.

Eden, C., and C. Böning, 2002: Sources of eddy kinetic energy in the Labrador Sea. J. Phys. Oceanogr., 32, 3346-3363, https:// doi.org/10.1175/1520-0485(2002)032<3346:SOEKEI $>2.0$.CO;2.

Ferrari, R., and C. Wunsch, 2009: Ocean circulation kinetic energy: Reservoirs, sources, and sinks. Annu. Rev. Fluid Mech., 41, 253-282, https://doi.org/10.1146/annurev.fluid.40. 111406.102139.

Fichefet, T., and M. Maqueda, 1997: Sensitivity of a global sea ice model to the treatment of ice thermodynamics and dynamics. J. Geophys. Res., 102, 12 609-12 646, https://doi.org/10.1029/ 97JC00480.

Gardner, W. D., B. E. Tucholke, M. J. Richardson, and P. E. Biscaye, 2017: Benthic storms, nepheloid layers, and linkage with upper ocean dynamics in the western North Atlantic. Mar. Geol., 385, 304-327, https://doi.org/10.1016/j.margeo.2016.12.012.

Geyer, F., S. Østerhus, B. Hansen, and D. Quadfasel, 2006: Observations of highly regular oscillations in the overflow plume downstream of the Faroe Bank Channel. J. Geophys. Res., 111, C12020, https://doi.org/10.1029/2006JC003693.

Gould, W., 1985: Physical oceanography of the Azores front. Prog. Oceanogr., 14, 167-190, https://doi.org/10.1016/0079-6611(85) 90010-2.

Greatbatch, R. J., 1987: A model for the inertial recirculation of a gyre. J. Mar. Res., 45, 601-634, https://doi.org/10.1357/ 002224087788326821
— A. F. Fanning, A. D. Goulding, and S. Levitus, 1991: A diagnosis of interpentadal circulation changes in the North Atlantic. J. Geophys. Res., 96, 22 009-22 023, https://doi.org/ 10.1029/91JC02423.

_ - X. Zhai, M. Claus, L. Czeschel, and W. Rath, 2010a: Transport driven by eddy momentum fluxes in the Gulf Stream Extension region. Geophys. Res. Lett., 37, L24401, https://doi. org/10.1029/2010GL045473.

__, _ _ J.-D. Kohlmann, and L. Czeschel, 2010b: Ocean eddy momentum fluxes at the latitudes of the Gulf Stream and the Kuroshio extensions as revealed by satellite data. Ocean Dyn., 60, 617-628, https://doi.org/10.1007/s10236-0100282-6.

Griffies, S. M., and Coauthors, 2009: Coordinated Ocean-ice Reference Experiments (COREs). Ocean Modell., 26, 1-46, https://doi.org/10.1016/j.ocemod.2008.08.007.

Guo, C., M. Ilicak, I. Fer, E. Darelius, and M. Bentsen, 2014: Baroclinic instability of the Faroe Bank Channel overflow. J. Phys. Oceanogr., 44, 2698-2717, https://doi.org/10.1175/ JPO-D-14-0080.1.

Harris, P. T., 2014: Shelf and deep-sea sedimentary environments and physical benthic disturbance regimes: A review and synthesis. Mar. Geol., 353, 169-184, https://doi.org/10.1016/ j.margeo.2014.03.023.

Hendry, R., 1982: On the structure of the deep Gulf Stream. J. Mar. Res., 40, 119-142.

Heuzé, C., K. J. Heywood, D. P. Stevens, and J. K. Ridley, 2015: Changes in global ocean bottom properties and volume transports in CMIP5 models under climate change scenarios. J. Climate, 28, 2917-2944, https://doi.org/10.1175/JCLI-D-1400381.1.

Hogg, N. G., 1983: A note on the deep circulation of the western North Atlantic: Its nature and causes. Deep-Sea Res., 30A, 945-961, https://doi.org/10.1016/0198-0149(83)90050-X.

_- 1992: On the transport of the Gulf Stream between Cape Hatteras and the Grand Banks. Deep-Sea Res., 39A, 12311246, https://doi.org/10.1016/0198-0149(92)90066-3.

_ circulation and the Gulf Stream. Deep-Sea Res., 32A, 11811193, https://doi.org/10.1016/0198-0149(85)90002-0.

Hollister, C., and I. McCave, 1984: Sedimentation under deepsea storms. Nature, 309, 220-225, https://doi.org/10.1038/ 309220a0.

Johns, W., T. Shay, J. M. Bane, and D. Watts, 1995: Gulf Stream structure, transport, and recirculation near $68^{\circ} \mathrm{W}$. J. Geophys. Res., 100, 817-838, https://doi.org/10.1029/94JC02497.

Jungclaus, J. H., J. Hauser, and R. H. Käse, 2001: Cyclogenesis in the Denmark Strait overflow plume. J. Phys. Oceanogr., 31, 3214-3229, https://doi.org/10.1175/1520-0485(2001)031<3214: CITDSO $>2.0 . \mathrm{CO} ; 2$.

Kämpf, J., 2005: Cyclogenesis in the deep ocean beneath western boundary currents: A process-oriented numerical study. J. Geophys. Res., 110, C03001, https://doi.org/10.1029/ 2003JC002206.

Kang, D., and E. N. Curchitser, 2015: Energetics of eddy-mean flow interactions in the Gulf Stream region. J. Phys. Oceanogr., 45, 1103-1120, https://doi.org/10.1175/JPO-D-14-0200.1.

Kontar, E., and A. Sokov, 1997: On the benthic boundary layer's dynamics. J. Mar. Syst., 11, 369-385, https://doi.org/10.1016/ S0924-7963(96)00131-5.

Large, W., and S. Yeager, 2009: The global climatology of an interannually varying air-sea flux data set. Climate Dyn., 33, 341-364, https://doi.org/10.1007/s00382-008-0441-3. 
Lazier, J. R., 1994: Observations in the northwest corner of the North Atlantic Current. J. Phys. Oceanogr., 24, 1449-1463, https://doi.org/10.1175/1520-0485(1994)024<1449:OITNCO> 2.0.CO;2.

Lee, T., and P. Cornillon, 1996: Propagation and growth of Gulf Stream meanders between $75^{\circ}$ and $45^{\circ} \mathrm{W}$. J. Phys. Oceanogr., 26, 225-241, https://doi.org/10.1175/1520-0485(1996) $026<0225$ :PAGOGS $>2.0 . \mathrm{CO} ; 2$.

Lindstrom, S. S., X. Qian, and D. R. Watts, 1997: Vertical motion in the Gulf Stream and its relation to meanders. J. Geophys. Res., 102, 8485-8503, https://doi.org/10.1029/96JC03498.

Lorenz, E. N., 1955: Available potential energy and the maintenance of the general circulation. Tellus, 7, 157-167, https:// doi.org/10.3402/tellusa.v7i2.8796.

Ma, X., and Coauthors, 2016: Western boundary currents regulated by interaction between ocean eddies and the atmosphere. Nature, 535, 533-537, https://doi.org/10.1038/nature18640.

Madec, G., and Coauthors, 2008: NEMO: The ocean engine. Institut Pierre-Simon Laplace Tech. Rep. 27, 217 pp.

Marshall, J., and G. Nurser, 1986: Steady, free circulation in a stratified quasi-geostrophic ocean. J. Phys. Oceanogr., 16, 1799-1813, https://doi.org/10.1175/1520-0485(1986)016<1799: SFCIAS $>2.0 . \mathrm{CO} ; 2$.

Meinen, C. S., 2001: Structure of the North Atlantic Current in stream-coordinates and the circulation in the Newfoundland basin. Deep-Sea Res. I, 48, 1553-1580, https://doi.org/10.1016/ S0967-0637(00)00103-5.

— , and D. S. Luther, 2016: Structure, transport, and vertical coherence of the Gulf Stream from the Straits of Florida to the Southeast Newfoundland Ridge. Deep-Sea Res. I, 112, $137-$ 154, https://doi.org/10.1016/j.dsr.2016.03.002.

Mertens, C., M. Rhein, M. Walter, C. W. Böning, E. Behrens, D. Kieke, R. Steinfeldt, and U. Stöber, 2014: Circulation and transports in the Newfoundland basin, western subpolar North Atlantic. J. Geophys. Res. Oceans, 119, 7772-7793, https://doi.org/10.1002/2014JC010019.

Parker, C. E., 1971: Gulf Stream rings in the Sargasso Sea. DeepSea Res. Oceanogr. Abstr., 18, 981-993, https://doi.org/10.1016/ 0011-7471(71)90003-9.

Phillips, N. A., 1951: A simple three-dimensional model for the study of large-scale extratropical flow patterns. J. Meteor., 8, 381-394, https://doi.org/10.1175/1520-0469(1951)008<0381: ASTDMF $>2.0 . \mathrm{CO} ; 2$.

Purkey, S. G., and G. C. Johnson, 2010: Warming of global abyssal and deep Southern Ocean waters between the 1990s and 2000s: Contributions to global heat and sea level rise budgets. J. Climate, 23, 6336-6351, https://doi.org/10.1175/2010JCLI3682.1.

Richardson, P., 1985: Average velocity and transport of the Gulf Stream near 55W. J. Mar. Res., 43, 83-111, https://doi.org/ 10.1357/002224085788437343.

Rieck, J. K., C. W. Böning, R. J. Greatbatch, and M. Scheinert, 2015: Seasonal variability of eddy kinetic energy in a global high-resolution ocean model. Geophys. Res. Lett., 42, 93799386, https://doi.org/10.1002/2015GL066152.

Savidge, D. K., and J. M. Bane, 1999a: Cyclogenesis in the deep ocean beneath the Gulf Stream: 1. Description. J. Geophys. Res., 104, 18111-18126, https://doi.org/10.1029/ 1999JC900132.

, and - 1999b: Cyclogenesis in the deep ocean beneath the Gulf Stream: 2. Dynamics. J. Geophys. Res., 104, 1812718140, https://doi.org/10.1029/1999JC900131.
Sen, A., R. B. Scott, and B. K. Arbic, 2008: Global energy dissipation rate of deep-ocean low-frequency flows by quadratic bottom boundary layer drag: Computations from currentmeter data. Geophys. Res. Lett., 35, L09606, https://doi.org/ 10.1029/2008GL033407.

Shay, T. J., J. M. Bane, D. R. Watts, and K. L. Tracey, 1995: Gulf Stream flow field and events near $68^{\circ} \mathrm{W}$. J. Geophys. Res., 100, 22 565-22 589, https://doi.org/10.1029/95JC02685.

Shriver, J. F., and H. E. Hurlburt, 2000: The effect of upper ocean eddies on the non-steric contribution to the barotropic mode. Geophys. Res. Lett., 27, 2713-2716, https://doi.org/10.1029/ 1999GL011105.

Smith, P. C., 1976: Baroclinic instability in the Denmark Strait overflow. J. Phys. Oceanogr., 6, 355-371, https://doi.org/ 10.1175/1520-0485(1976)006<0355:BIITDS > 2.0.CO;2.

Steele, M., R. Morley, and W. Ermold, 2001: PHC: A global ocean hydrography with a high-quality Arctic Ocean. J. Climate, 14, 2079-2087, https://doi.org/10.1175/1520-0442(2001)014<2079: PAGOHW $>2.0 . \mathrm{CO} ; 2$.

Sutyrin, G. G., I. Ginis, and S. A. Frolov, 2001: Equilibration of baroclinic meanders and deep eddies in a Gulf Streamtype jet over a sloping bottom. J. Phys. Oceanogr., 31, 2049-2065, https://doi.org/10.1175/1520-0485(2001)031<2049: EOBMAD $>2.0 . \mathrm{CO} ; 2$.

Thompson, J. D., and W. Schmitz, 1989: A limited-area model of the Gulf Stream: Design, initial experiments, and modeldata intercomparison. J. Phys. Oceanogr., 19, 791-814, https:// doi.org/10.1175/1520-0485(1989)019<0791:ALAMOT> 2.0.CO;2.

von Storch, J.-S., C. Eden, I. Fast, H. Haak, D. HernándezDeckers, E. Maier-Reimer, J. Marotzke, and D. Stammer, 2012: An estimate of the Lorenz energy cycle for the World Ocean based on the STORM/NCEP simulation. J. Phys. Oceanogr., 42, 2185-2205, https://doi.org/10.1175/JPO-D-12079.1 .

Wang, Y., M. Claus, R. J. Greatbatch, and J. Sheng, 2017: Decomposition of the mean barotropic transport in a high-resolution model of the North Atlantic Ocean. Geophys. Res. Lett., 44, $11537-11546$, https://doi.org/10.1002/ 2017 GL074825.

Watts, D. R., and W. E. Johns, 1982: Gulf Stream meanders: Observations on propagation and growth. J. Geophys. Res., 87, 9467-9476, https://doi.org/10.1029/JC087iC12p09467.

, K. L. Tracey, J. M. Bane, and T. J. Shay, 1995: Gulf Stream path and thermocline structure near $74^{\circ} \mathrm{W}$ and $68^{\circ} \mathrm{W}$. J. Geophys. Res., 100, 18291-18312, https://doi.org/10.1029/ 95JC01850.

Worthington, L. V., 1976: On the North Atlantic Circulation. Johns Hopkins University Press, $110 \mathrm{pp}$.

Zalesak, S. T., 1979: Fully multidimensional flux-corrected transport algorithms for fluids. J. Comput. Phys., 31, 335-362, https://doi.org/10.1016/0021-9991(79)90051-2.

Zhai, X., and D. P. Marshall, 2013: Vertical eddy energy fluxes in the North Atlantic subtropical and subpolar gyres. J. Phys. Oceanogr., 43, 95-103, https://doi.org/10.1175/ JPO-D-12-021.1.

Zhang, R., and G. K. Vallis, 2007: The role of bottom vortex stretching on the path of the North Atlantic western boundary current and on the northern recirculation gyre. J. Phys. Oceanogr., 37, 2053-2080, https://doi.org/10.1175/JPO3102.1. 